\title{
O GRAU DE SATISFAÇÃO DOS AGRICULTORES FAMILIARES EM RELAÇÃ̃O AO PROGRAMA DE AQUISIÇÃ̃O DE ALIMENTOS
}

\section{THE DEGREE OF SATISFACTION OF FAMILY FARMERS IN RELATION TO THE FOOD ACQUISITION PROGRAM}

\author{
Recebido em 18.01.2017. Aprovado em 02.05.2017 \\ Avaliado pelo sistema double blind review \\ DOI: http://dx.doi.org/10.12712/rpca.v11i2.894
}

\section{Daniel Teotonio Nascimento}

danielteotonio@hotmail.com

Universidade Federal da Integração Latino-Americana (UNILA), Foz do Iguaçu/PR, BRASIL

\section{Jerry Adriani Johann}

jerry.johann@hotmail.com

Universidade Estadual do Oeste do Paraná (UNIOESTE), Cascavel/PR, BRASIL

\section{Dirceu Basso}

dirceu.basso@unila.edu.br

Universidade Federal da Integração Latino-Americana (UNILA), Foz do Iguaçu/PR, BRASIL

\section{Resumo}

Este estudo teve como objetivo comprovar o grau de satisfação de 69 agricultores familiares em relação ao Programa de Aquisição de Alimentos (PAA), bem como o seu grau de satisfação em relação à gestão de uma Cooperativa do Oeste do Paraná dos quais são filiados. No desenvolvimento da pesquisa foi utilizado o Modelo de Avaliação de Satisfação (MAS), desenvolvido por Nascimento (2015), constatando-se que em geral os agricultores familiares estão satisfeitos em relação ao PAA e a gestão da Cooperativa. Entretanto, alguns produtores manifestaram insatisfação, especialmente quanto aos preços pagos por seus produtos, aos grupos prioritários, e às documentações exigidas. Quanto à gestão da Cooperativa, também foram detectados alguns indicadores negativos. Portanto, foram realizadas duas propostas de intervenção: uma direcionada aos órgãos públicos e outra aos diretores da Cooperativa.

Palavras-chave: Políticas Públicas; Programa de Aquisição de Alimentos (PAA); Modelo de Avaliação de Satisfação (MAS); Cooperativas; Intervenções.

\section{Abstract}

This study aimed to verify the degree of satisfaction of 69 farmers in relation to the Food Acquisition Program, as well as their degree of satisfaction with the management of the West of Paraná Cooperative of which are affiliated. On the development of research was used the Satisfaction Evaluation Model developed by Nascimento (2015), being verified that in general the family farmers are satisfied with respect to the Food Acquisition Program and the management of the Cooperative. However, some producer manifested dissatisfaction, especially with regard to the prices paid for their products, the priority groups, and the required documentation. In relation to the management of the Cooperative, some negative indicators were also detected. Therefore, two intervention proposals were made: one directed to public agencies and another to the directors of the Cooperative.

Keywords: Public Policies; Food Acquisition Program; Satisfaction Evaluation Model; Cooperatives; Interventions. 


\section{Introdução}

A participação social nos processos de discussão, elaboração, gestão e controle das políticas públicas foi uma das principais reivindicações defendida pelos agentes sociais no processo de redemocratização brasileira, ocorrido na década de 80 . Como efeito dessa mobilização, a Constituição Federal de 1988 introduziu novos instrumentos de gestão social das políticas públicas, o que motivou o início da participação da sociedade civil nas ações governamentais, como foi o caso dos atores relacionados com a agricultura familiar (SILVA; MARQUES, 2009).

Com isto, a dívida histórica com a agricultura familiar, começou a ser saldada somente a partir dos anos 90, pois apesar de a agricultura familiar desempenhar um importante papel na segurança alimentar e na geração de emprego no campo, o Estado sempre lhe dispensou um tratamento marginal ou secundário (MAIA, 2009).

Em virtude do reconhecimento da multifuncionalidade da agricultura familiar durante as últimas duas décadas, o setor rural passou a despertar mais a atenção dos agentes públicos e da sociedade. Segundo o Censo Agropecuário de 2006, a agricultura familiar contava com cerca de 4,4 milhões de estabelecimentos, respondia por $38 \%$ do valor total da produção agropecuária com $\mathrm{R} \$ 54,4$ bilhões, era responsável pela segurança alimentar e empregava $74,4 \%$ da mão-deobra no campo, ou seja, 12,3 milhões de trabalhadores, além do gerenciamento de uma área de 80,25 milhões de hectares (INSTITUTO BRASILEIRO DE GEOGRAFIA E ESTATÍSTICA, 2006).

Nesse contexto de tentativa de valorização da agricultura familiar, o Governo criou em 28 junho de 1996, por meio do Decreto n. ${ }^{\circ} 1946$ (1996), o Programa Nacional de Fortalecimento da Agricultura Familiar (PRONAF), com a finalidade de promover o desenvolvimento sustentável do segmento rural, constituído pelos agricultores familiares, de modo a propiciar-lhes o aumento da capacidade produtiva, a geração de empregos e a melhoria de renda. Foi a partir da institucionalização do Pronaf que o conceito do termo 'agricultura familiar' foi se tornando menos ideológico e mais operacional, estabelecendo critérios e características para acessar ao programa governamental.

Outras políticas públicas complementares também foram desenvolvidas nos últimos anos, talvez visando corrigir imperfeições do Pronaf e, ao mesmo tempo, buscando sintonia com o Programa Fome Zero como é o caso do Programa de Aquisição de Alimentos (PAA), instituído em junho de 2003. O PAA é uma política pública no qual são adquiridos alimentos dos agricultores familiares que se enquadram no Pronaf, sendo esses alimentos destinados à formação de estoques de segurança ou canalizados para populações em situação de risco alimentar (COMPANHIA NACIONAL DE ABASTECIMENTO, 2009; GRISA; SCHNEIDER, 2014; TANACA; SOUZA; GANGA, 2014).

Atualmente o PAA é operacionalizado através de seis modalidades distintas, porém o foco deste estudo está centrado na modalidade de Compra com Doação Simultânea (CDS). Participam do PAA a União, Estados, Distrito Federal e Municípios. O grau de envolvimento de cada ente é estabelecido de acordo com a modalidade. No âmbito federal, a maioria das modalidades é gerenciada pelo Ministério de Desenvolvimento Social (MDS), com a cooperação efetiva da Companhia Nacional de Abastecimento (CONAB) na operacionalização do programa, sendo o elo entre os estados, municípios e os agricultores familiares.

Desde 2003 o PAA vem aumentando seu campo de atuação, atendendo cada vez mais os beneficiários, sejam recebedores - pessoas com risco de insegurança alimentar -, ou fornecedores - agricultores familiares. A modalidade CDS é a que possui maior movimentação nas operações, tanto em volume de recursos, como em número de agricultores familiares atendidos. Seu objetivo é "promover a articulação entre a produção da agricultura familiar e a destinação dessa produção, visando o atendimento direto às demandas de alimentação ou de suplementação alimentar e nutricional dos programas sociais e o desenvolvimento da economia local" (CONAB, 2016, s. p.).

Os produtos adquiridos da agricultura familiar abastecem os órgãos públicos de alimentação e nutrição e também as ações de acesso à alimentação empreendidas por entidades da rede sócio assistencial local. Para participar da CDS os agricultores familiares devem estar organizados em cooperativas ou associações, devem possuir a Declaração de Aptidão ao Pronaf (DAP) e precisam encaminhar Proposta de Participação à CONAB.

Aprovada a Proposta de Participação, a cooperativa emite uma Cédula de Produto Rural (CPR-Doação) e 
os agricultores familiares passam a fornecer alimentos às entidades conforme definido na Proposta. Após a confirmação da entrega dos produtos, a CONAB disponibiliza os recursos pactuados na conta da cooperativa, que realiza o pagamento aos agricultores. $\mathrm{Na}$ execução pela CONAB, as cooperativas de agricultores entregam os produtos diretamente nas entidades beneficiárias. Por exemplo, na cidade de Foz do Iguaçu/PR, os produtos são adquiridos dos agricultores familiares, associados da Cooperativa da Agricultura Familiar e Solidária do Oeste do Paraná (COAFASO), que é a entidade responsável pela proposta de entrega dos produtos. Posteriormente, os agricultores entregam os produtos ao Banco de Alimentos do Município, que os recebe segundo os critérios estabelecidos pela $\mathrm{CONAB}$, e os repassam aos beneficiários, selecionados pelo município, conforme o grau de vulnerabilidade alimentar. Neste caso, os recursos financeiros para execução do PAA são repassados pelo MDS para a $\mathrm{CONAB}$, que fica responsável pelo pagamento aos agricultores.

O limite de participação dos agricultores por unidade familiar/ano é de $\mathrm{R} \$$ 8.000,00 (oito mil reais) que participarem por meio de organizações da agricultura familiar, via CONAB.

Considerando a importância dessa política pública nacional para o meio rural, torna-se imprescindível verificar o grau de satisfação de um de seus principais atores, os agricultores familiares, pois são eles que desencadeiam todo o processo da política pública PAA, e sem a efetiva participação desses pequenos agricultores, as metas do programa não são alcançadas.

Alguns estudos já abordaram os impactos do PAA, diretos ou indiretos para os agricultores familiares. Tais pesquisas revelam que os impactos são diferenciados, a depender da modalidade do PAA, da região, das entidades participantes e das unidades executoras. Nascimento et al. (2015) consolidaram esses resultados em cincos categorias: resultados positivos; resultados positivos e negativos de maneira concomitante; resultados pouco perceptíveis, porém negativos; resultados pouco perceptíveis, porém positivos. Ressalta-se que em nenhum estudo verificaram-se somente impactos negativos do PAA. Porém, foram observadas debilidades em alguns indicadores do PAA, como a falta de capacitação dos agricultores familiares; problemas na e para a gestão das cooperativas ou associações; falta de parcerias locais; baixo valor por produtor; e baixo limite de entrega por agricultor.

Observou-se que não houve, nos estudos realizados, umapreocupaçãoemavaliara satisfaçãodos agricultores familiares, por meio de Modelos abrangentes, que incluísse uma variedade significativa de indicadores. Isso é um problema, pois tem impossibilitado, de certa maneira, os ajustes necessários à política pública, por meio de tomadas de decisões mais eficazes.

Considerando que a cidadania almeja uma gestão eficiente do Estado, faz-se necessário um acompanhamento constante das políticas públicas em execução. Neste sentido, esta pesquisa contribui com o campo de avaliações de políticas públicas, bem como para uma maior visibilidade dos agricultores familiares, importantes atores do meio rural brasileiro.

O objetivo deste estudo foi avaliar o grau de satisfação dos agricultores familiares em relação ao Programa PAA, modalidade CDS, do Governo Federal. Além disso, considerando a importância das cooperativas e associações na operacionalização do PAA, também se verificou o grau de satisfação dos agricultores familiares em relação à gestão da cooperativa, na qual os agricultores estavam filiados.

\section{Fundamentação Teórica}

Nesta seção, são abordadas as temáticas da agricultura familiar; políticas públicas; o Programa de Aquisição de Alimentos (PAA); bem como estudos anteriores sobre o tema.

\section{Agricultura Familiar}

A pequena propriedade rural tem passado por significativas mudanças desde a década de 1970. Esse cenário de instabilidade forçou os agricultores familiares a se unirem e a defenderem seus espaços como atores protagonistas do desenvolvimento rural brasileiro.

Apesar de a agricultura familiar ocupar um importante papel na segurança alimentar e no abastecimento interno, esse setor sempre conviveu com uma dicotomia, pois o Estado sempre lhe dispensou um tratamento secundário. Somente nos últimos anos houve um planejamento de políticas públicas voltadas a esse segmento rural (SILVA; MARQUES, 2009). 
Mesmo com o avanço do debate social e acadêmico, nota-se que não há um entendimento único, uma exclusividade e delimitação estrita do conceito de agricultura familiar, apesar de não ser um termo propriamente novo. Sua origem está atrelada ao surgimento da agricultura moderna, pois sempre houve pequenos agricultores que cultivaram em suas próprias terras e comercializavam o excedente. O termo pode estar relacionado a critérios como: tamanho da propriedade, quem administra a terra, tempo de trabalho da família, dentre outros. Percebe-se ainda, que esses critérios foram estabelecidos considerando contextos políticos, étnicos, socioeconômicos e ambientais da época (SCHMITZ; MOTA, 2008).

Agricultura familiar é uma forma de produção onde predomina a interação entre gestão e trabalho. São os agricultores familiares que dirigem o processo produtivo, dando ênfase na diversificação e utilizando o trabalho familiar, eventualmente complementado pelo trabalho assalariado (MINISTÉRIO DO DESENVOLVIMENTO AGRÁRIO, 2016).

Nas últimas décadas, tem-se visto uma evolução significativa de modelos de produção agropecuária e de alimentos que atendem a requisitos específicos e diferenciados dos modelos convencionais, como a Agricultura Orgânica (PÉREZ, 2011). Assim, a agricultura orgânica assume maior legitimidade com a crescente preocupação da opinião pública a respeito dos impactos ambientais (SCHULTZ, 2011).

O pequeno produtor cumpre sua função social e ambiental quando consegue produzir sem agredir o meio ambiente. Utiliza os recursos naturais finitos, de forma racional e adequada, visando à manutenção do equilíbrio ecológico e à garantia da saúde, da qualidade de vida e do bem-estar social e econômico dos potenciais consumidores e dos próprios membros da agricultura familiar (MALLMANN et al., 2013).

É importante também considerar a conceituação de agricultor familiar segundo o Pronaf, pois somente tem acesso ao Programa de Aquisição de Alimentos os agricultores familiares quem dispõe de Declaração de Aptidão do Pronaf (DAP). Em 1995, por meio da Resolução CMN/BACEN no 2.191 (1995), entrou em vigência o PRONAF, e naquele momento houve uma primeira conceituação do agricultor familiar. Essa conceituação no âmbito do Pronaf passou por algumas modificações durante essas duas décadas, e hoje estão vigentes critérios relacionados às condições de exploração, residência, tamanho da propriedade, percentual de renda advinda da propriedade e limites, limite de contratação de assalariado. (BANCO CENTRAL DO BRASIL, 2016).

Nota-se que muitas das ações dos agricultores familiares são desenvolvidas por meio do cooperativismo. O cooperativismo é um movimento, filosofia de vida e modelo socioeconômico, capaz de unir desenvolvimento econômico e bem-estar social. Suas referenciais fundamentais são a participação democrática, solidariedade, independênciaeautonomia. O cooperativismo está associado a valores universais e se desenvolve independentemente de território, língua, credo ou nacionalidade (ORGANIZAÇÃO DAS COOPERATIVAS BRASILEIRAS, 2016).

Nesse mesmo sentido, Gawlak (2007) indica que o cooperativismo moderno está baseado nos seguintes princípios: adesão voluntária elivre; gestão democrática; participação econômica dos associados; autonomia e independência; educação, formação e informação; cooperação entre as cooperativas; e interesse pela comunidade. Esses princípios permitem que o cooperativismo seja uma alternativa socioeconômica que leva ao sucesso do grupo, com equilíbrio e justiça. Assim, nota-se que, nas cooperativas, os cooperados dispõem de liberdade e independência de ações. É essa relação que os mantêm na cooperativa.

Considerando o contexto do cooperativismo rural a partir dos anos de 1970, nota-se que o cooperativismo surgiu como uma alternativa aos produtores, em resposta à competitividade dos mercados. Além disso, as cooperativas propiciaram o fortalecimento da união entre os cooperados, antes isolados em suas propriedades, permitindo o compartilhamento de suas ansiedades, responsabilidades e custos (ANDRADE; ALVES, 2013). Com a maior competitividade e exigência dos consumidores, quem mais sofre no setor rural são os pequenos produtores organizados em pequenas cooperativas e associações.

Segundo Nazzari e Zimmermann (2015), o associativismo forte pode congregar estilos mais adaptáveis de cooperação com consequente melhoria da qualidade de vida dos cooperados. O desenvolvimento e a sustentabilidade da propriedade rural familiar proporcionam o fomento com visão orientada para produção, transformação e comercialização dos produtos. Para tanto, demandase assistência técnica e capacitação aos cooperadores, 
para gestão econômica e solução dos gargalos da comercialização da produção.

No atual contexto de complexidade e competitividade, as cooperativas, como qualquer organização, devem ser geridas de maneira eficaz e eficiente, buscando, além de criar um ambiente de sinergia entre cooperativa e política pública (PAA), satisfazer seus próprios cooperados. Para isso, torna-se importante a realização de pesquisas junto aos cooperados, visando identificar suas percepções sobre a gestão do empreendimento, bem como dos programas públicos dos quais os cooperados participam.

\section{Políticas Públicas}

Dentre os acontecimentos mais marcantes que ocorreram na esfera das políticas públicas para o meio rural brasileiro, a partir da década dos 90, pode-se destacar a criação do Programa Nacional de Fortalecimento da Agricultura Familiar (Pronaf). $\mathrm{O}$ surgimento deste programa representou o reconhecimento e a legitimação do Estado em relação às especificidades de uma nova categoria social - os agricultores familiares -, que até então era designada por pequenos produtores, produtores familiares, produtores de baixa renda ou agricultores de subsistência. Ou seja, a política pública foi criada em um contexto de pressão dos agricultores familiares, dados seus problemas vivenciados, especialmente quanto à dificuldade de comercialização de seus produtos (SCHNEIDER; CAZELLA; MATTEI, 2009).

Assim, as políticas públicas são criadas para revolver problemas de uma determinada coletividade. Uma política pública possui dois elementos fundamentais: intencionalidade pública e resposta a um problema público. Em outras palavras, a razão para o estabelecimento de uma política pública é o tratamento ou a resolução de um problema entendido como coletivamente relevante (SECCHI, 2013).

Uma política pública é um conjunto de princípios e critérios e linhas de ação que garantem e permitem a gestão do Estado na solução de problemas nacionais. Considerando que o Estado foi criado para permitir o bem-estar dos indivíduos, as políticas públicas são mecanismos utilizados pelos governos, capazes de garantir que os cidadãos possam buscar a felicidade, de forma equitativa, sem que sejam prejudicados pelas ações de outros indivíduos ou organizações
(DIAS; MATOS, 2012). Algumas políticas podem ser consideradas de Estados, enquanto outras são apenas de governos.

O processo de elaboração de políticas públicas também é conhecido como ciclo de políticas públicas. O ciclo de políticas públicas é um esquema de visualização e interpretação que organiza a vida de uma política pública em fases sequenciais e interdependentes. Para Secchi (2013), o ciclo de políticas públicas é composto das seguintes fases: 1) identificação do problema, 2) formação da agenda, 3) formulação de alternativas, 4) tomada de decisão, 5) implementação, 6) avaliação, e 7) extinção. Como o foco deste estudo é avaliativo, centrou-se em detalhar a fase de avaliação.

A avaliação de política pública é um processo de julgamentos deliberados sobre a validade de propostas para a ação pública. Consiste na mensuração, bem como na análise dos resultados produzidos. O conceito de avaliação da política pública trata, em termos amplos, da fase ou estágios do processo em que se determina como uma política pública de fato está funcionando na prática, consistindo em avaliar os meios em que são empregados e verificando se os objetivos estão sendo atingidos (HEIDEMANN; SALM, 2014).

A avaliação é uma ferramenta importante, pois permite ao Governo e/ou Estado realizar uma série de ações em função dos resultados obtidos, dentre os quais: gerar informações úteis para futuras políticas públicas; prestar contas de seus atos; justificar as ações e explicar seus atos; responder se o recursos, que são escassos, estão produzindo os resultados esperados e da forma mais eficiente possível; identificar as barreiras que impedem o sucesso de um programa; e promover o diálogo entre os vários atores individuais e coletivos envolvidos (DIAS; MATOS, 2012).

Quanto ao uso das avaliações das políticas públicas, os resultados alcançados, envolvem, fundamentalmente, quatro possibilidades: instrumental, conceitual, como instrumento de persuasão e para o esclarecimento (FARIA, 2005).

Nota-se que existem diferentes maneiras de se realizar uma avaliação de políticas públicas, a depender do ator, do foco, do objetivo e da complexidade do programa público. Uma pesquisa de satisfação com os beneficiários de uma determinada política pública é uma forma de avaliação. Obter respostas sobre o êxito ou não de uma determinada política pública é 
fundamental para quem se interessa em conhecer a atuação governamental, em avaliar seu grau de eficácia e eficiência e em conhecer os efeitos de sua intervenção, seus acertos e seus erros. A avaliação acadêmica é outra forma de avaliar os programas públicos, sendo mais formal, e focaliza a efetividade das políticas, seus impactos e benefícios, tendo como vantagem uma maior isenção e rigor científico (JANNUZZI, 2011). Esse autor ainda explica que cada tipo de estudo avaliativo requer uma abordagem metodológica e/ou disciplina diferente.

\section{Programa de Aquisição de Alimentos}

O Programa de Aquisição de Alimentos da Agricultura Familiar (PAA) é uma política pública criada pelo Governo Federal, instituído por meio do artigo 19, da Lei $\mathrm{n}^{\circ}$ 10.696, de 02 de julho de 2003, no âmbito do Programa Fome Zero. A Lei no 10.696 foi alterada pela Lei $n^{\circ} 12.512$, de 14 de outubro de 2011. Com mais de 13 anos de vigência, o PAA já foi regulamentado por diversos decretos, resoluções e portaria. Desde 4 de julho de 2012, está vigente o Decreto no 7.775 (2012) - apesar das alterações promovidas pelo Decreto n. ${ }^{\circ}$ 8.293 de 12 de agosto de 2014.

O PAA conta com a participação dos entes da Federação, Estados, Distrito Federal e municípios como parceiros executores. Essa política pública, além de contribuir com a segurança alimentar de grupos em riscos, desde 2012, passou também a integrar o eixo - Inclusão Produtiva - do Plano Brasil sem Miséria, que tem como objetivo erradicar a pobreza extrema e melhorar as condições de bem-estar da população (MINISTÉRIO DO DESENVOLVIMENTO SOCIAL E COMBATE À FOME, 2016a).

A política pública PAA possui duas finalidades básicas: promover o acesso à alimentação e incentivar a agricultura familiar. Os processos de comercialização por meio do PAA são mais simplificados, sendo dispensada a realização de processos licitatórios para a compra dos produtos da agricultura familiar. $\mathrm{O}$ Programa efetua a compra de alimentos produzidos pela agricultura familiar com dispensa de licitação e os destina às pessoas em situação de insegurança alimentar e nutricional e àquelas atendidas pela rede socioassistencial, pelos equipamentos públicos de segurança alimentar e nutricional e pela rede pública e filantrópica de ensino (HESPANHOL, 2013).

São objetivos do PAA, segundo a Lei no 10.696 (2003), promulgada em 02 de julho: a) incentivar a agricultura familiar; b) incentivar o consumo e a valorização dos alimentos produzidos pela agricultura familiar; c) promover o acesso à alimentação em quantidade, qualidade e regularidade necessárias, das pessoas em situação de insegurança alimentar e nutricional; d) promover o abastecimento alimentar, que compreende as compras governamentais de alimentos, incluída a alimentação escolar; e) apoiar a formação de estoques pelas cooperativas e demais organizações formais da agricultura familiar; f) fortalecer circuitos locais e regionais e redes de comercialização. A participação no PAA é estimulada, tanto pela inclusão de agricultores cadastrados, quanto pelo aumento de consumidores destes alimentos, famílias em situação de vulnerabilidade alimentar. (MINISTÉRIO DO DESENVOLVIMENTO SOCIAL E COMBATE À FOME, 2016b).

No sentido de atender aos objetivos da Lei de criação do PAA, o programa encontra-se estruturado em 6 modalidades. Como já mencionado, a avaliação neste artigo foi referente à Modalidade CDS que possui as características conforme o Quadro 1. 
Quadro 1 . Características da modalidade Compra com Doação Simultânea (CDS)

\begin{tabular}{|c|c|c|c|c|}
\hline Modalidade & Conceito & $\begin{array}{l}\text { Forma de } \\
\text { acesso }^{(1)}\end{array}$ & $\begin{array}{c}\text { Limites } \mathbf{R} \$ / \\
\text { por ano }\end{array}$ & $\begin{array}{c}\text { Origem do } \\
\text { Recurso }\end{array}$ \\
\hline $\begin{array}{c}\text { Compra da } \\
\text { Agricultura } \\
\text { Familiar para } \\
\text { Doação Simultânea } \\
\text { - CDS }\end{array}$ & $\begin{array}{l}\text { A Modalidade Compra com Doação Simultânea } \\
\text { promove a articulação entre a produção da } \\
\text { agricultura familiar e as demandas locais de } \\
\text { suplementaçãoalimentar, além do desenvolvimento } \\
\text { da economia local. Os produtos adquiridos dos } \\
\text { agricultores familiares são doados às pessoas } \\
\text { em insegurança alimentar, por meio da rede } \\
\text { socioassistencial ou equipamentos públicos de } \\
\text { segurança alimentar e à rede pública e filantrópica } \\
\text { de ensino. A Compra com Doação Simultânea - } \\
\text { CDS permite a aquisição de alimentos in natura } \\
\text { ou processados, enriquecendo os cardápios dos } \\
\text { beneficiários consumidores. O fornecimento de } \\
\text { produtos orgânicos é privilegiado, sendo possível } \\
\text { incluir até } 30 \% \text { a mais do que o valor pago para o } \\
\text { alimento convencional. }\end{array}$ & Organizações & $\begin{array}{l}\mathrm{R} \$ 6,5 \text { mil ou } \\
\mathrm{R} \$ 8 \text { mil (via } \\
\text { organização) }\end{array}$ & MDS \\
\hline
\end{tabular}

(1) O beneficiário fornecedor poderá participar de mais de uma modalidade e os limites serão independentes entre si. (2) Respeitando os limites por unidade familiar.

Fonte: Adaptado do MDS (2015b)

Ao observar a Plataforma de Indicadores do Governo Federal (PGI, 2015) foi possível constatar que, no período de 2003 a 2014, os volumes de recursos - todas as modalidades do PAA - repassados à política pública tiveram tendência crescente até 2012, passando de 145 milhões em 2003, para 838 milhões em 2012, depois havendo uma redução em 2013 e 2014. Por outro lado, notou-se que as modalidades do PAA mais utilizadas foram a Compra com Doação Simultânea (CDS) e o Incentivo à Produção e Consumo do Leite, no período de 2003-2010. Dados do Ministério do Desenvolvimento Social têm demonstrado que a tendência tem sido a mesma para o período de 2011-2014, mantendo-se a modalidade de Compra com Doação Simultânea (CDS) como aquela que mais recebe recursos do PAA, com um percentual de 66\%.

Dessa forma, considerando que a modalidade do PAA de CDS é a que mais recebe recursos e a que envolve um maior número de agricultores familiares, justifica-se assim, a avaliação da satisfação referente à essa modalidade.

\section{Estudos Anteriores sobre o Tema}

Devido à necessidade de verificação dos resultados efetivos dos programas públicos, no intuito de atender às exigências dos cidadãos/clientes, os governos e pesquisadores têm avaliado nos últimos anos, diferentes tipos de políticas públicas, desde as mais tradicionais, como saúde e educação, passando até as áreas sociais e políticas do desenvolvimento rural.

Para subsidiar a discussão sobre a avaliação do PAA, utilizou-se do levantamento da produção científica realizado por Nascimento et al. (2015), no período de março e abril de 2015, no qual investigaram a produção científica sobre o tema durante a última década (2005 a março/2015). O referido levantamento das produções científicas buscou identificar todos os aspectos avaliativos sobre o PAA, que investigaram a gestão da política pública e/ ou as percepções de um dos atores do PAA. Dessa forma, destacaram-se como principais resultados positivos do PAA e que repercutem diretamente ou indiretamente na percepção de satisfação dos agricultores familiares, fatores como: valorização da agricultura familiar; incentivo à uma alimentação saudável para a população; apoio à sustentabilidade ambiental; melhoria de qualidade de vida dos agricultores familiares; e incentivo ao associativismo. Como fatores susceptíveis de melhorias: apoio à capacitação gerencial das associações e 
agricultores familiares; melhoria do preço de compra dos alimentos; equilíbrio da distribuição dos recursos do programa aos Estados; falta de conhecimento dos gestores públicos sobre o programa, dentre outros.

\section{0 modelo de avaliação de satisfação}

O modelo desenvolvido por Nascimento (2015), foi concebido a partir de três variáveis principais, para identificar a percepção dos agricultores familiares: Variável I - perfil dos agricultores familiares; Variável II - grau de satisfação sobre os efeitos do PAA - CDS; Variável III - grau de satisfação sobre a eficiência da cooperativa ou associação (Figura 1).

O modelo de avaliação da satisfação (MAS) foi composto por três etapas (Figura 2).

\section{Etapa I - Definição da organização onde seria aplicado o MAS aos agricultores familiares}

Nesta etapa é selecionada uma Organização (Cooperativa ou Associação) fornecedora de Produtos do PAA. Vale destacar que, na Modalidade de Compra com Doação Simultânea (CDS-CONAB), as entregas dos Produtos só podem ocorrer por meio de uma Organização, ou seja, individualmente é vedado aos agricultores familiares realizarem a entrega dos produtos às unidades recebedoras. Recomenda-se, portanto, incluir na população todos os agricultores familiares que participaram de algum projeto do PAACDS, independentemente do ano, no intuito de se alcançar uma população significativa e, assim, permitir uma amostra coerente e válida estatisticamente.

Figura 1. Concepção do Modelo de Avaliação de Satisfação (MAS)

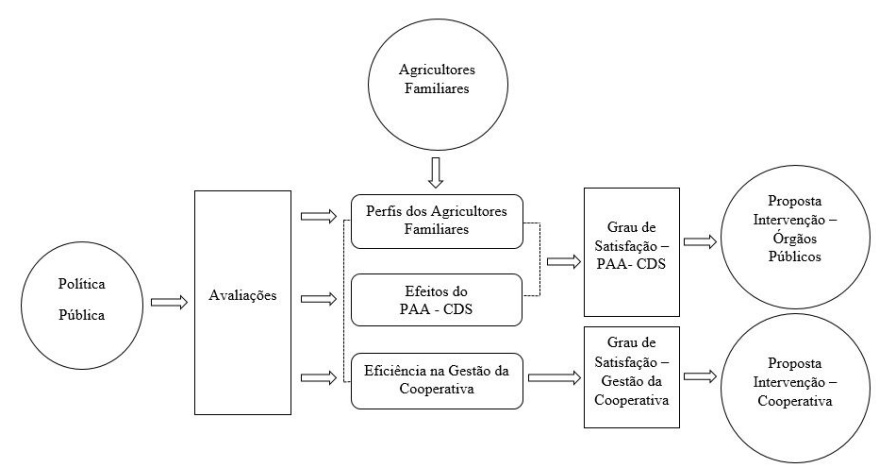

Fonte: Nascimento (2015, pg. 26).
Figura 2. Etapas do MAS

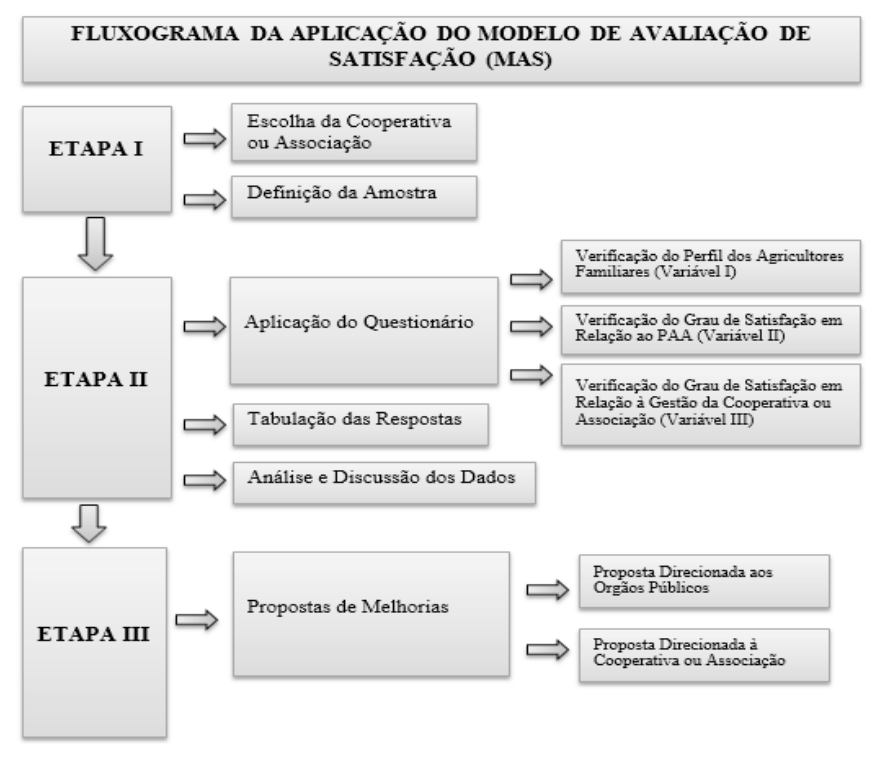

Fonte: Adaptado de Nascimento (2015, pg. 56/59).

\section{Etapa II - Aplicação do Instrumento de Pesquisa, tabulação e discussão dos resultados dos dados}

O Modelo foi construído utilizando uma estrutura composta por questões associadas a uma escala do tipo Likert. A escala do MAS correspondeu a ' $0=$ Muito Insatisfeito'; '1 = Insatisfeito'; '2 = Indeciso/ Neutro'; ‘3 = Satisfeito’; ‘4 = Muito Satisfeito'. A escala de pontos foi escolhida devido à possibilidade de sua transformação em escala somada e por permitir a obtenção de escores de pontuação.

A Variável I - Caracterização dos agricultores familiares participantes do PAA (questões 01 a 18) do modelo de avaliação (Quadro 2) foi organizada para levantar dados inexistentes nas bases de dados dos órgãos executores da política pública, e com base nisto, entender as possíveis potencialidades e gargalos do programa. 
Quadro 2 . Variável I - Caracterização dos agricultores familiares participantes do PAA

\section{VARIÁVEL I}

\section{CARACTERIZAÇÃO DO AGRICULTORES FAMILIARES PARTICIPANTES DO PAA}

1. Há quantos anos está neste município?
a.( ) 1 a 5 anos
b.( ) 6 a 10 anos
c.( ) acima de 11 anos

2. Há quantos anos trabalha no meio rural?
a.( ) 1 a 5 anos
c.( ) acima de 11 anos
b.( ) 6 a 10 anos

3. Qual o tamanho da sua propriedade rural? hectares OU alqueires.

4. Há quantos anos é produtor familiar?
a.( ) 1 a 5 anos
b.( ) 6 a 10 anos
c.( ) acima de 11 anos

5. Qual é a quantidade de membros de sua família que trabalha na agricultura familiar?
a.( ) 1 a 2
c.( ) acima de 5
b.( ) 3 a 4

6. Como ficou sabendo do PAA pela primeira vez?
a.( ) Cooperativa
b.( ) Gov. Estadual
c.( ) CONAB
d.( ) Prefeitura
e.( ) Organizações de assistência e extensão rural
f.( ) Outro. Qual:

7. Em que ano realizou a primeira entrega do PAA?

8. Quando você começou a fazer parte da Cooperativa ou Associação para entregar pelo PAA?

a.( ) Já era associado antes do PA.A

b.( ) Me associei para participar do PAA

9. Qual foi o motivo de sua entrada no PAA?
a.( ) aumento da renda
b.( ) preço pago pelo PAA
c.( ) é mais fácil vender
d.( ) a convite da Cooperativa ou Associação
e.( ) Outro. Qual:

10. Você participa de outras modalidades do PAA, além da Compra com Doação Simultânea?

a.( ) Não

b.( ) Sim, então escolha a modalidade abaixo:

b1.[ ] Compra com Doação Simultânea (individual)

b2.[ ] Compra Institucional

b3.[ ] Formação de Estoque

b4.[ ] PAA-Leite

b5.[ ] Compra Antecipada
11. Você participa da entrega de produtos ao PAA, diretamente, sem a participação da Cooperativa ou Associação?
a.( ) Não
b.( ) $\operatorname{Sim}$

12. Já teve produtos recusados pela Unidade Recebedora, como por exemplo, por questões de qualidade?
a.( ) Não
b.( ) $\operatorname{Sim}$

13. Em relação aos orgânicos você já pensou em iniciar essa produção, dado seu maior preço de venda?
a.( ) Não
b.( ) $\mathrm{Sim}$
c.( ) Já produzo orgânicos

14. Você já deixou de entregar algum produto que estava combinado na proposta da cooperativa ou associação? a.( ) Não, sempre entreguei o combinado

b.( ) Sim, mas troquei por outros produtos

c.( ) Sim, pois não aceitaram a troca

15. Qual a principal dificuldade para participar do PAA?
a.( ) Documentação
b.( ) Qualidade dos Produtos
c.( ) Quantidade minima exigida de produtos
d.( ) Outras

16. Conhece agricultores/pessoas que ficaram sabendo do PAA (Compra com Doação Simultânea) e não participaram?

a.( ) Não

b.( ) Sim, então escolha a motivo abaixo:

b1.[ ] Muito complicado

b2.[ ] Faltaram documentos

b3.] ] Não eram da Cooperativa ou Associação.

b4.[ ] Outros:

17. Em sua opinião, se o Programa PAA acabar, a Produção na Agricultura Familiar?
a.( ) Se mantém
b.( ) Diminui
c.( ) Não tem relação direta, pois só entrego o excesso da produção.

18. Em sua opinião, se o Programa PAA acabar, a comercialização na Agricultura Familiar?
a.( ) Se mantém
b.( ) Diminui
c.( ) Não tem relação direta, pois tenho outros meios de comercialização.

Fonte: Nascimento (2015, pg. 103). 
Assim, a finalidade foi caracterizar os agricultores familiares, em relação aos seguintes indicadores: dados sobre a atividade rural, a propriedade, o número de membros da família; motivo da participação no PAA; filiação junto às cooperativas; relacionamento com as cooperativas e unidades recebedoras; início da participação no PAA e quantidade de modalidades que participam; predisposição para a produção de orgânicos; êxito na entrega dos produtos do PAA; principal dificuldade para participar no PAA; e impactos do PAA sobre a produção e a comercialização. De posse destes dados foi possível traçar o perfil predominante dos agricultores familiares, possibilitando o direcionamento de ações ao público alvo predominante ou a pequenos grupos não contemplados na política pública.

$\mathrm{Na}$ Variável II do MAS (Quadro 3 - questões 19 a 41), o foco foi verificar o grau de satisfação dos agricultores familiares, considerando as diversas dimensões da Política Pública, avaliando indicadores provenientes das seguintes categorias: informação e capacitação; grupos prioritários do PAA; documentação exigida pelo PAA; questões operacionais do PAA; aspectos financeiros do PAA; os efeitos do PAA na produção; os efeitos sociais do PAA.

Após a coleta dos dados da Variável II (Quadro 3), eles devem ser tabulados utilizando o Quadro 4, ou seja, multiplicando-se o número de vezes de cada resposta (a) pela respectiva pontuação (pesos) a ela atribuída (b). Após somados (c), divide-se pelo número de questões relacionadas à satisfação dos agricultores familiares (d), conforme Bertolini, Rojo e Lezana (2012).

Em seguida, tem-se a quantificação do Grau de Satisfação dos agricultores familiares (Quadro 5) em relação ao PAA-CDS, definida a partir dos resultados das Escalas Likert, nas quais eles indicaram seu grau de concordância ou discordância relativas ao tema.

Finalmente, na Variável III do modelo MAS (Quadro 6 - Questões 42 a 51), a finalidade é verificar o grau de satisfação dos agricultores familiares em relação à forma da gestão da Cooperativa, por meio dos indicadores: grau de participação da proposta do PAA; procedimentos dos PAA repassados pela Cooperativa ou Associação; apoio operacional da Cooperativa ou Associação; grau de oportunidade dada aos cooperados; atendimento e resolução de conflitos dos cooperados; grau de participação nas assembleias gerais; estratégias adotadas pela cooperativa ou associação para celebração de parcerias; e transparências das informações e dos canais de reclamações

Em seguida, segue-se para a Variável III, o mesmo procedimento de tabulação dos dados (Quadros 4 e 5), porém, avaliando o Grau de Satisfação em relação à gestão da cooperativa.

No intuito de avaliar novas percepções e grau de satisfação dos agricultores familiares, o MAS recomenda a realização de análise bidimensional, com aplicação do teste de independência, entre algumas questões das variáveis I, II e III, no intuito de averiguar a existência de associações significativas entre o perfil dos entrevistados e seus graus de satisfação. Com isto, é possível identificar efeitos negativos e positivos do PAA-CDS, segundo à percepção e satisfação dos agricultores familiares, bem como os feedbacks em relação à forma de gestão da Cooperativa. 
Quadro 3 . Variável II - Grau de satisfação em relação ao PAA

VARIÁVEL II

GRAU DE SATISFAC̣̃̃O EM RELAC̣ÃO AO PROGRAMA DE AQUISIC̣ÃO DE ALIMENTOS (PAA)

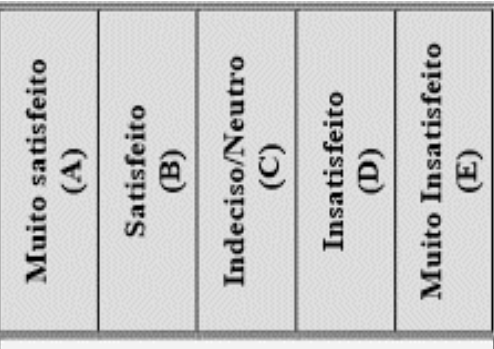

Em relação às informações/capacitações recebidas indique o grau de satisfação: $\quad$ Assinalar somente uma alternativa

19. Com as organizações de assistência e extensão rural.

20. Com o apoio recebido pelo governo (prefeitura, Estado ou CONAB).

21. Com o PAA, considerando as explicações/treinamento para o entendimento

sobre a Modalidade de Compra com Doação Simultânea.

Em relação aos grupos prioritários do PAA indique o grau de satisfação:

Com os grupos prioritários definidos pelo MDS (CadUnico; assentados;

22. indigenas, quilombolas e comunidades tradicionais; mulheres; e produtos orgânicos ou agroecológicos).

23. Com o percentual de $40 \%$ de mulheres e $5 \%$ de orgânicos, como obrigatórios na Compra com Doação Simultânea.

Em relação às documentações exigidas pelo PAA indique o grau de satisfação:

24. Com as exigências para a obtenção da DAP.

25. Com o PAA, considerando as documentações exigidas (CPF e DAP).

26. Com as condições e obrigações estabelecidas no termo de compromisso.

Em relação às questões operacionais do $\mathrm{PAA}$ indique o grau de satisfação:

27. Com os critérios de qualidade estabelecidos, no momento da entrega dos produtos.

28. Com os produtos solicitados para compor a proposta à CONAB, refletindo as caracteristicas da região.

29. Com relação à embalagem dos produtos, pois recebo ajuda da prefeitura ou da CONAB.

30. Com relação ao transporte do produto, pois recebo ajuda da prefeitura ou da CONAB.

Em relação aos aspectos financeiros do PAA indique o grau de satisfação:

31. Com os preços pagos por meus produtos pelo PAA.

32. Com o PAA, pois permitiu o aumento de minha renda.

33 Com o PAA, pois o preço pago por meus produtos me permite cobrir os custos de produção.

Em relação aos efeitos na produção indique o grau de satisfação:

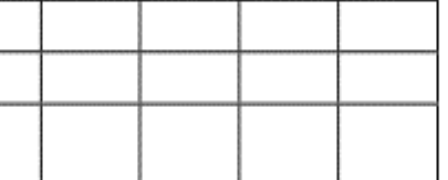

Assinalar somente uma alternativa

34. Com o PAA, pois me ajudou na compra de bens móveis como carro, moto, caminhão, trator, roçadeira ou arados.

35. Com o PAA, pois com o programa passei a produzir novos produtos.

36. Ao PAA, pois com o Programa aumentei minha área de produção.

37. Com o PAA, pois passei a utilizar novas tecnologias, como irrigação, máquinas/implementos ou agricultura orgânica.

Em relação aos efeitos sociais do PAA indique o grau de satisfação:

38. Com o PAA, pois me ajudou na compra de bens duráveis como geladeira,

38. celular, televisão, computador ou antena parabólica.

Somente responder se tiver filhos em idade escolar (até 18 anos)

39. Como o PAA, pois me ajudou para que meus filhos continuassem na escola ou que voltassem a estudar.

40. Com o PAA, pois mesmo fornecendo para o Programa, não deixei de consumir nenhum produto para vender para o PAA.

41. Com o funcionamento do PAA como política pública de ajuda ao agricultor familiar.

Fonte: Nascimento (2015, pg. 104). 
Quadro 4 . Alocação de Pesos e Elaboração do Grau de Satisfação dos Agricultores Familiares

\begin{tabular}{|c|c|c|}
\hline $\begin{array}{c}\text { (a) } \mathbf{N}^{\mathbf{0}} \\
\text { Respostas }\end{array}$ & (b) Pesos & (a X b) Resultado \\
\hline A & 4 & \\
B & 3 & \\
C & 2 \\
D & 1 & \\
E & 0 & \\
\hline \multicolumn{2}{|c|}{ (c) Soma dos Resultados } \\
(d) $\mathrm{N}^{\text {o de questões }}$ \\
(e = c / d) Resultado
\end{tabular}

Fonte: Adaptado de Bertolini, Rojo e Lezana (2004, p. 578).

Quadro 05 . Classificação do Grau de Satisfação dos Agricultores Familiares

\begin{tabular}{|l|l|}
\hline \multicolumn{1}{|c|}{$\begin{array}{c}\text { Grau de satisfação em } \\
\text { relação ao PAA }\end{array}$} & \multicolumn{1}{|c|}{ Valores } \\
\hline A) Está altamente satisfeito & Entre 3,3 e 4,0 \\
\hline B) Está satisfeito & Entre 2,5 e 3,2 \\
\hline $\begin{array}{l}\text { C) Está indeciso sobre os } \\
\text { efeitos do PAA }\end{array}$ & Entre 1,7 e 2,4 \\
\hline D) Está insatisfeito & Entre 0,9 e 1,6 \\
\hline E) Está altamente insatisfeito & Até 0,8 \\
\hline
\end{tabular}

Fonte: Adaptado de Brandalise (2008, p. 192)

Quadro 6 . Variável III - Grau de satisfação em relação à gestão da Cooperativa

\begin{tabular}{|c|c|c|c|c|c|c|}
\hline & $\begin{array}{c}\text { VARIÁVEL III } \\
\text { GRAU DE SATISFAÇÃO EM RELAC̣Ão ÀS ORGANIZAÇÕES } \\
\text { FORNECEDORAS DO PAA } \\
\text { (COOPERATIVAS OU OUTRAS ASSOCLAÇÕES) }\end{array}$ & 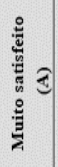 & 递 & 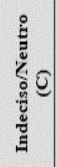 & 总 & 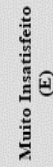 \\
\hline \multicolumn{2}{|r|}{$\begin{array}{l}\text { Em relação aos aspectos de gestão da Cooperativa ou Associação indique o } \\
\text { grau de satisfação: }\end{array}$} & \multicolumn{5}{|c|}{ Assinalar somente uma alternativa } \\
\hline 42. & $\begin{array}{l}\text { Com o nivel de sua participação na elaboração da proposta do PAA pela } \\
\text { Cooperativa ou Associação. }\end{array}$ & & & & & \\
\hline 43. & $\begin{array}{l}\text { Com a assistência da Cooperativa ou Associação sobre os procedimentos } \\
\text { do PAA. }\end{array}$ & & & & & \\
\hline 44. & $\begin{array}{l}\text { Com o apoio operacional da Cooperativa ou Associação (ajuda para } \\
\text { embalagens, transporte e certificação de orgânicos). }\end{array}$ & & & & & \\
\hline 45. & $\begin{array}{l}\text { Com as oportunidades dadas pela Cooperativa ou Associação para a } \\
\text { participação de todos os cooperados. }\end{array}$ & & & & & \\
\hline 46. & Com a forma como os diretores/as dialogam e atendem os associados as & & & & & \\
\hline 47. & $\begin{array}{l}\text { Com a forma de participação nas Assembleias Gerais da Cooperativa ou } \\
\text { Associaçăo. }\end{array}$ & & & & & \\
\hline 48. & $\begin{array}{l}\text { Com as formas adotadas pelos diretores da Cooperativa ou Associação para } \\
\text { resolver os conflitos entre a cooperativa ou Associação e os filiados }\end{array}$ & & & & & \\
\hline 49. & $\begin{array}{l}\text { Com as estratégias da Cooperativa ou Associação para alcançar novas } \\
\text { parcerias. }\end{array}$ & & & & & \\
\hline 50. & $\begin{array}{l}\text { Com a transparência das informações da Cooperativa ou Associação aos } \\
\text { filiados. }\end{array}$ & & & & & \\
\hline 51. & Com os canais de reclamações existentes. & & & & & \\
\hline
\end{tabular}

Fonte: Nascimento (2015, pg. 104).

\section{Etapa III - Proposta de Intervenção na Política Pública}

Esta etapa consiste na realização de propostas de melhorias ou de intervenções. A primeira proposição de melhoria na política pública do PAA é direcionado aos órgãos públicos competentes (MDS e CONAB), com base no grau de satisfação dos fornecedores dos produtos desse programa - agricultores familiares -, no sentido de atenuar possíveis debilidades do PAA.

A segunda proposta de melhoria é orientada aos diretores das Cooperativas e Associações, apresentando-lhes possíveis alternativas para minimizar as prováveis insatisfações dos cooperados, em relação à forma de gestão da organização.

As proposições de melhorias devem ser focadas, principalmente, nos indicadores que receberem avaliações ruins - "Insatisfeito" e "Muito Insatisfeito".

\section{Metodologia}

Quanto aos fins, a pesquisa foi descritiva e explicativa. Descritiva, considerando que se avaliaram percepções, expectativas e grau de satisfação dos agricultores familiares em relação a uma política pública. Explicativa, pois visou explicar a razão de alguns fenômenos observados. Quanto aos meios, a pesquisa foi bibliográfica, documental, de campo e estudo de caso. Bibliográfica, pois se analisaram diversos materiais como livros, artigos, dissertações, teses, leis, decretos e resoluções, visando à fundamentação teórica do tema. A pesquisa também foi documental, porque utilizou-se de relatórios e documentos de trabalhos internos da Cooperativa COAFASO. A pesquisa foi de campo, porque coletou dados primários junto aos agricultores familiares participantes do PAA-CDS. Por fim, possuiu caráter de estudo de caso, considerando que se investigou em profundidade uma determinada população. Cabe mencionar ainda que a taxionomia utilizada nesta pesquisa foi a sugerida por Vergara (2007).

Os sujeitos desta pesquisa foram os agricultores familiares da região Oeste do Paraná associados à COAFASO, fornecedores de alimentos do PAA, modalidade CDS. Os agricultores familiares associados da COAFASO (incluindo matriz e filiais), participantes do PAA-CDS, entre o período de 2012 e 2014, foram 
contemplados com as seguintes propostas: a) ano de 2012, por meio da Matriz de Foz do Iguaçu, com a participação de 69 produtores; b) ano de 2012, por meio da filial de Medianeira, com a participação de 69 produtores e; c) ano de 2014, por meio da filial de Missal, com 60 produtores.

Entretanto, segundo o presidente da COAFASO e especialistas da área em estudo, não existiam diferenças relevantes em relação aos perfis dos agricultores participantes das três propostas citadas, visto que a maioria dos requisitos já eram préestabelecidos pelo próprio PAA. Basicamente, o que diferenciou as propostas foram os tipos e quantidades de produtos entregues ao PAA. Diante disto, definiuse uma avaliação censitária com os 69 produtores de Foz do Iguaçu que participaram da proposta de 2012 (entrega dos produtos 2012/2013), por facilidade de deslocamento para obtenção dos dados primários.

\section{Resultados da pesquisa}

Nesta seção são apresentados os resultados da aplicação do MAS.

\section{Etapa I - Definição da organização para a aplicação do Modelo MAS}

Nesta primeira etapa da aplicação do Modelo, o objetivo foi encontrar uma organização (cooperativa ou associação), para o desenvolvimento da pesquisa empírica.

A Cooperativa da Agricultura Familiar e Solidária do Oeste do Paraná (COAFASO) foi fundada no dia 18 de outubro do ano de 2011, com sede na cidade de Foz do Iguaçu, região Oeste do Paraná, com área de ação em todo o estado do Paraná. Tem como objetivos estimular a produção, a recepção, a armazenagem e a comercialização de produtos, oriundos da agricultura familiar de seus associados ou de terceiros. A cooperativa vem atuando nestes segmentos de mercado em sua área de ação e, portanto, em mercados convencionais locais, no varejo - através de três lojas próprias de venda, localizadas em Foz do Iguaçu, Medianeira e Missal -, e em mercados institucionais em quatro municípios de sua área de atuação - Foz do Iguaçu, Medianeira, Missal e Santa Terezinha de Itaipu. Assim, além da realização da comercialização em canais convencionais (lojas próprias e feiras itinerantes), a COAFASO participa do PNAE e PAA. Os principais produtos da organização são frutas, verduras, panificados, mel, bebidas e sucos e demais produtos coloniais.

A COAFASO possuía, em outubro de 2015, 340 cooperados filiados. Eles adquiriram uma cota da cooperativa, no valor de $\mathrm{R} \$ 100,00$, que lhes dão direito de participar nas decisões da organização. Para cada projeto da COAFASO, há despesas operacionais inerentes à sua execução, que são compartilhadas entre os cooperados participantes desses projetos específicos. Quanto ao faturamento, a receita operacional bruta da cooperativa está na faixa de 2 a 3 milhões de reais anuais (ano-base: 2015).

Dessa forma, e conforme dados já apresentados anteriormente, verificou-se que a COAFASO possuía o perfil adequado para aplicação do Modelo.

\section{Etapa II - Aplicação do instrumento de pesquisa, tabulação e discussão dos resultados}

O formulário de pesquisa, foi aplicado durante os meses de agosto e setembro de 2015, de maneira censitária, a 69 agricultores familiares filiados à COAFASO, pertencentes ao município de Foz do Iguaçu e regiões limítrofes.

\section{VARIÁVEL I - Caracterização dos agricultores familiares participantes do PAA}

Após a consolidação das respostas, foi possível traçar o perfil predominante dos agricultores familiares da COAFASO. Os agricultores vivem há mais de 11 (onze) anos no município exercendo suas atividades no meio rural. Nestas últimas décadas, a partir dos anos 1990, esses agricultores experimentaram um ambiente institucional no qual foram, desde então, estabelecidas políticas públicas com o propósito de reduzir a pobreza, bem como para uma melhoria na qualidade de vida. Assim, desde os anos 1960 e 1970 no qual as políticas de modernização do espaço rural provocaram profundas transformações, em particular nos aspectos de produção agrícola, passando pelos anos de 1980 com processos de lutas sociais e maior participação na definição das ações do Estado, as famílias passam por relevantes ajustes em seus projetos produtivos. O PAA significa uma das oportunidades para os agricultores ampliarem suas possibilidades de ajustes em seus projetos de produção, objetivando sua permanência futura no meio rural. 
Os produtores que contam com uma média de 8 (ha) de terra e possuem entre 3 a 4 membros em seu núcleo familiar, que foram os mais destacados, encontram-se vinculados a diversas redes sociais com o propósito de viabilizar seus empreendimentos econômicos. Além de participarem enquanto membros do quadro social da cooperativa COAFASO, possuem vínculos com ONGs - Centro de Apoio e Promoção da Agroecologia (CAPA) e a Cooperativa de Trabalho e Assistência Técnica do Paraná (BIOLABORE) ambas que prestam serviços técnicos e de extensão em consonância com as políticas públicas. Ainda, procuram realizar processos comerciais a partir das ações de desenvolvimento desencadeadas pela Prefeitura Municipal.

A inserção dessas famílias nessas redes sociais contribuiu para que no decorrer da existência do PAA elas pudessem aumentar significativamente sua participação na operacionalização do Programa, com destaque para o ano de 2012 no qual se constitui a COAFASO. De acordo com os dados, a maioria $(73,6 \%)$ das famílias ingressaram na política pública objetivando o aumento de renda. Este fato corrobora com os demais estudos, entre eles o de Schneider, Cazella e Mattei (2009), que revelam as dificuldades vivenciadas pelos produtores para inserirse nos mercados, em particular para o comércio de commodities, cujas vendas demandam cada vez mais uma produção em escala, com um determinado padrão de qualidade e de forma continuada. Diante disso, os agricultores encontraram no(s) mercados institucionais (PAA, Pronaf e Pnae) uma saída para o escoamento da produção.

Fazer uma agricultura com base nos princípios orgânicos é o que desejam a maioria os produtores, conscientes de seu papel na preservação dos recursos naturais finitos, de forma mais racional e adequada, possuindo assim, o perfil identificado por Mallmann et al., (2013). Esta conduta, ou seja, produzir de modo diferenciado à lógica convencional (intensiva em escala, produtividade e capital financeiro) se apresenta com legitimidade diante da opinião pública e das novas políticas para o setor. Fato que revela uma sintonia de valores quanto às preocupações dos diversos atores - agricultores, governo, sociedade - sobre as questões socioeconômicas e ambientas em favor do desenvolvimento rural sustentável. Potencializar esses valores de sustentabilidade, com ênfase na agricultura familiar e com políticas afins, atende de forma substancial a função social e ambiental dos agricultores por parte expressiva da sociedade.

Contudo, os agricultores envolvidos no estudo, se por um lado destacaram que em sua maioria realizaram entregas com êxito de acordo com a proposta inicial cadastrada no Programa, por outro, 66,6\% disseram apresentar sérias dificuldades em atender as solicitações quanto à documentação do PAA. Esta situação pode ser explicada, em parte, pela própria história do agricultor familiar, pois em períodos anteriores seus conhecimentos estavam mais dirigidos a produção para fins de abastecimento familiar e comercializam o excedente produtivo. Portanto, eram os próprios agricultores, com sua autonomia, que dirigiam seus sistemas de produção. Nos dias atuais, diante das grandes transformações ocorridas nas atividades agropecuárias das últimas décadas, os agricultores necessitam estar com capacidades (profissionalizados) para atuar em diferentes canais de mercados. Capacidades essas que são desenvolvidas e atendidas na medida em que participam de redes sociais que atendem as demandas por conhecimentos, como exemplos as ONGs e as Cooperativas.

Caso o PAA venha a sofrer redução em sua operacionalização, devido a diversos fatores, as famílias entrevistadas (91,2\%) argumentaram que poderão sim sofrer impactos, tanto sobre a produção quanto sobre a inserção neste mercado institucional. Isso permite observar a importância do PAA para a melhoria da qualidade de vida das famílias e para o desenvolvimento local. Portanto, dialogando com outros estudos, entre eles o de Dias e Matos (2012), constata-se que o PAA necessita ser tratado como política de Estado, e não de governo, considerando os expressivos impactos que causaria em uns de seus principais atores, ou seja, os agricultores familiares.

\section{VARIÁVEL II - Grau de satisfação em relação ao programa de aquisição de alimentos}

As proporções das questões (19 a 41) são resumidas no Quadro 07. No geral, cada grau de satisfação obteve as seguintes proporções: muito satisfeito (17\%); satisfeito $(50 \%)$; indeciso/neutro $(12 \%)$; insatisfeito $(20 \%)$; muito insatisfeito (1\%).

Observou-se que a classificação de satisfeito foi a mais assinalada (50\%), com destaque para as questões $32,37,38$ e 40 . Os dados indicam que os agricultores $(72 \%)$ estão satisfeitos em relação ao aumento de 
renda possibilitado pelo PAA. De certa forma, isso pode ser percebido como uma amenização de um dos principais gargalos na agricultura familiar, a dificuldade de inserir-se nos canais de comercialização. Dessa forma, a política pública PAA auxilia significativamente a socialização e inserção dos agricultores familiares nos mercados, entendendo esses mercados como espaços sociais (redes, campos, arenas), resultantes das interações entre os agricultores e os demais atores públicos e privados (CONTERATO, at al 2011). Este fato, qual seja, a satisfação com o aumento da renda, permite verificar o quanto necessário se faz a presença do Estado e Governo com políticas públicas a favor das categorias sociais mais fragilizadas, mas com enorme potencial para contribuir com o processo de desenvolvimento rural.

Quadro 07 . Proporção de Respostas da Variável II - Grau de Satisfação PAA

\begin{tabular}{|c|c|c|c|c|c|c|}
\hline \multicolumn{2}{|r|}{$\begin{array}{l}\text { VARIÁVEL II } \\
\text { GRAU DE SATISFAÇÃO EM RELAÇÃO AO PROGRAMA DE AQUISIÇÃO DE } \\
\text { ALIMENTOS (PAA) }\end{array}$} & 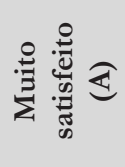 & 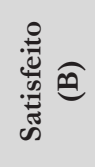 & 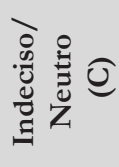 & 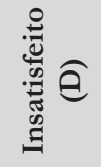 & 裉 \\
\hline \multicolumn{7}{|c|}{ Em relação às informações/capacitações recebidas, indique o grau de satisfação: } \\
\hline 19. & Com as organizações de assistência e extensão rural & $33,3 \%$ & $63,1 \%$ & $1,8 \%$ & $1,8 \%$ & $0 \%$ \\
\hline 20. & Com o apoio recebido pelo governo (prefeitura, Estado ou CONAB) & $17,5 \%$ & $45,6 \%$ & $31,7 \%$ & $5,2 \%$ & $0 \%$ \\
\hline 21. & $\begin{array}{l}\text { Com o PAA, considerando as explicações/treinamento para o entendimento sobre } \\
\text { a Modalidade de CDS }\end{array}$ & $14,1 \%$ & $64,9 \%$ & $10,5 \%$ & $10,5 \%$ & $0 \%$ \\
\hline \multicolumn{7}{|c|}{ Em relação aos grupos prioritários do PAA, indique o grau de satisfação: } \\
\hline 22. & $\begin{array}{l}\text { Com os grupos prioritários definidos pelo MDS (CadUnico; assentados; indígenas, } \\
\text { quilombolas e comunidades tradicionais; mulheres; e produtos orgânicos ou } \\
\text { agroecológicos) }\end{array}$ & $3,5 \%$ & $3,5 \%$ & $12,3 \%$ & $73,7 \%$ & $7,0 \%$ \\
\hline 23. & $\begin{array}{l}\text { Com o percentual de } 40 \% \text { de mulheres e } 5 \% \text { de orgânicos, como obrigatórios na } \\
\text { Compra com Doação Simultânea }\end{array}$ & $38,6 \%$ & $54,3 \%$ & $5,3 \%$ & $1,8 \%$ & $0 \%$ \\
\hline \multicolumn{7}{|c|}{ Em relação à documentação exigida pelo PAA, indique o grau de satisfação: } \\
\hline 24. & Com as exigências para a obtenção da DAP & $1,8 \%$ & $49,1 \%$ & $35,1 \%$ & $14,0 \%$ & $0 \%$ \\
\hline 25. & Com o PAA, considerando a documentação exigida (CPF e DAP) & $7,0 \%$ & $14,0 \%$ & $5,3 \%$ & $73,7 \%$ & $0 \%$ \\
\hline 26. & Com as condições e obrigações estabelecidas no termo de compromisso & $10,5 \%$ & $19,3 \%$ & $10,5 \%$ & $57,9 \%$ & $1,8 \%$ \\
\hline \multicolumn{7}{|c|}{ Em relação às questões operacionais do PAA, indique o grau de satisfação: } \\
\hline 27. & $\begin{array}{l}\text { Com os critérios de qualidade estabelecidos, no momento da entrega dos } \\
\text { produtos }\end{array}$ & $26,3 \%$ & $70,1 \%$ & $1,8 \%$ & $1,8 \%$ & $0 \%$ \\
\hline 28. & $\begin{array}{l}\text { Com os produtos solicitados para compor a proposta à CONAB, refletindo as } \\
\text { características da região }\end{array}$ & $15,8 \%$ & $42,1 \%$ & $31,6 \%$ & $10,5 \%$ & $0 \%$ \\
\hline 29. & $\begin{array}{l}\text { Com relação à embalagem dos produtos, pois recebo ajuda da prefeitura ou da } \\
\text { CONAB }\end{array}$ & $8,8 \%$ & $19,3 \%$ & $26,3 \%$ & $45,6 \%$ & $0 \%$ \\
\hline 30. & $\begin{array}{l}\text { Com relação ao transporte do produto, pois recebo ajuda da prefeitura ou da } \\
\text { CONAB }\end{array}$ & $12,5 \%$ & $23,2 \%$ & $21,4 \%$ & $42,9 \%$ & $0 \%$ \\
\hline \multicolumn{7}{|c|}{ Em relação aos aspectos financeiros do PAA, indique o grau de satisfação: } \\
\hline 31. & Com os preços pagos por meus produtos pelo PAA & $0 \%$ & $10,5 \%$ & $24,6 \%$ & $61,4 \%$ & $3,5 \%$ \\
\hline 32. & Com o PAA, pois permitiu o aumento de minha renda & $17,5 \%$ & $72,0 \%$ & $7,0 \%$ & $3,5 \%$ & $0 \%$ \\
\hline 33. & $\begin{array}{l}\text { Com o PAA, pois o preço pago por meus produtos me permite cobrir os custos } \\
\text { de produção }\end{array}$ & $29,8 \%$ & $63,2 \%$ & $3,5 \%$ & $3,5 \%$ & $0 \%$ \\
\hline \multicolumn{7}{|c|}{ Em relação aos efeitos na produção, indique o grau de satisfação: } \\
\hline 34. & $\begin{array}{l}\text { Com o PAA, pois me ajudou na compra de bens móveis como carro, moto, } \\
\text { caminhão, trator, roçadeira ou arados }\end{array}$ & $7,0 \%$ & $54,4 \%$ & $8,8 \%$ & $29,8 \%$ & $0 \%$ \\
\hline 35. & Com o PAA, pois com o programa passei a produzir novos produtos & $12,3 \%$ & $70,2 \%$ & $14,0 \%$ & $3,5 \%$ & $0 \%$ \\
\hline
\end{tabular}




\begin{tabular}{|c|c|c|c|c|c|c|}
\hline \multicolumn{2}{|r|}{$\begin{array}{c}\text { VARIÁVEL II } \\
\text { GRAU DE SATISFAÇÃO EM RELAÇÃO AO PROGRAMA DE AQUISIÇÃO DE } \\
\text { ALIMENTOS (PAA) }\end{array}$} & \multirow{2}{*}{ 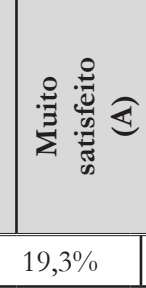 } & \multirow{2}{*}{ 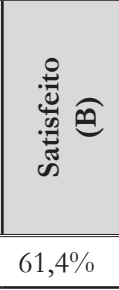 } & \multirow{2}{*}{ 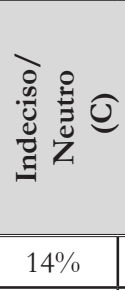 } & \multirow{2}{*}{ 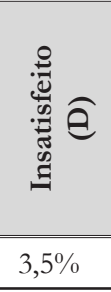 } & \multirow{2}{*}{ 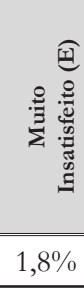 } \\
\hline 36. & Ao PAA, pois com o Programa aumentei minha área de produção & & & & & \\
\hline 37. & $\begin{array}{l}\text { Com o PAA, pois passei a utilizar novas tecnologias, como irrigação, máquinas/ } \\
\text { implementos ou agricultura orgânica }\end{array}$ & $14,0 \%$ & $71,9 \%$ & $8,8 \%$ & $3,5 \%$ & $1,8 \%$ \\
\hline \multicolumn{7}{|c|}{ Em relação aos efeitos sociais do PAA, indique o grau de satisfação: } \\
\hline 38. & $\begin{array}{l}\text { Com o PAA, pois me ajudou na compra de bens duráveis como geladeira, celular, } \\
\text { televisão, computador ou antena parabólica }\end{array}$ & $14,0 \%$ & $77,2 \%$ & $1,8 \%$ & $7,0 \%$ & $0 \%$ \\
\hline 39. & $\begin{array}{l}\text { Somente responder se tiver filhos em idade escolar (até } 18 \text { anos) } \\
\text { Como o PAA, pois me ajudou para que meus filhos continuassem na escola ou } \\
\text { que voltassem a estudar }\end{array}$ & $20,0 \%$ & $68,0 \%$ & $8,0 \%$ & $4,0 \%$ & $0 \%$ \\
\hline 40. & $\begin{array}{l}\text { Com o PAA, pois mesmo fornecendo para o Programa, não deixei de consumir } \\
\text { nenhum produto para vender para o PAA }\end{array}$ & $26,3 \%$ & $71,9 \%$ & $1,8 \%$ & $0 \%$ & $0 \%$ \\
\hline 41. & $\begin{array}{l}\text { Com o funcionamento do PAA como política pública de ajuda ao agricultor } \\
\text { familiar }\end{array}$ & $36,8 \%$ & $61,4 \%$ & $1,8 \%$ & $0 \%$ & $0 \%$ \\
\hline \multicolumn{2}{|c|}{ Total absoluto } & 214 & 635 & 161 & 260 & 10 \\
\hline \multicolumn{2}{|c|}{ Total geral } & $17 \%$ & $50 \%$ & $12 \%$ & $20 \%$ & $1 \%$ \\
\hline
\end{tabular}

Fonte: Dados da pesquisa de campo (2015).

A satisfação das famílias pode ser observada a partir de diversos aspectos. Entre eles, destaca-se a possibilidade da introdução de novas tecnologias no processo produtivo. Este aspecto das tecnologias, como os demais que veremos a seguir, nos permite perceber as diferentes maneiras de como a dinâmica do desenvolvimento rural pode ser enriquecida com vistas a melhoria das condições de vida. O PAA permite investimento nas propriedades, através da aquisição de ferramentas e maquinários, possibilitando uso de novas técnicas e manejos no processo produtivo, impactando positivamente na melhoria dos processos produtivos. E isso é um indicador positivo desta política pública, conforme apontado também no estudo Rossi (2012), que indicou esses aspectos positivos do programa: relacionados à condição de vida, uso do solo da propriedade, produção vegetal, investimentos na propriedade, acesso à extensão rural e informação, práticas agrícolas, gestão da qualidade dos produtos, dentre outros.

Declararam estarem satisfeitos quanto à possibilidade de melhoria da renda, permitindo comprar bens duráveis para melhorar o bem-estar familiar. Esse indicador é importante uma vez que a política pública auxiliou, em certa medida, na melhoria da qualidade de vida dos agricultores, cumprindo assim, com um dos objetivos do PAA (CONAB, 2016). Alguns dos agricultores familiares revelaram que a partir do momento que iniciaram a participação no PAA, foi possível mobiliar suas residências, principalmente com a aquisição de novos elétricos domésticos.

Estão satisfeitos em relação à segurança alimentar familiar, pois mesmo entregando produtos ao PAA, mantiveram um sistema produtivo que permanece oferecendo uma boa produção de subsistência à família. Os dados indicaram que até o momento não existe o risco de comprometer a segurança alimentar em favor da busca monetária no mercado. Pois as condutas dos agricultores ao inserir-se nos mercados institucionais, como o possibilitado pelo PAA, mantêm presente e fortalece a lógica da produção diversificada. Os produtos comercializados, os quais abrange uma diversidade grande de produtos - processados ou não, também são os mesmos utilizados para o consumo das famílias. Assis, Priore e Franceschini (2017), tiveram essa mesma preocupação em sua pesquisa, e corroboraram que o PAA ao incentivar o cultivo diversificado, impacta positivamente tanto para comercialização quanto para o autoconsumo das famílias, contribuindo positivamente para uma realidade de Segurança Alimentar e Nutricional dos agricultores. 
Quanto aos agricultores que demonstraram estar insatisfeitos (20\%), destacaram-se as questões 22,25 e 31, revelando que discordavam de alguns aspectos do programa. Para esses agricultores insastifeitos, no que se refere aos grupos prioritários estabelecidos pelo MDS (Questão 22 - CadUnico; assentados; indígenas, quilombolas e comunidades tradicionais; mulheres; e produtos orgânicos ou agroecológicos), verifica-se que existe problemas na participação destas categorias sociais de acordo com os agricultores que estão operando com o PAA. Para eles, essas categorias não desejam participar da proposta de entrega. Esse indicador trata-se de uma política afirmativa governamental, que considera que há categorias sociais - entre os de economia familiar -, que estão ainda mais fragilizados em termos de qualidade de vida e inserção no mercado. Considerando o caráter provisório dessa prioridade estabelecida, parece ser adequado que os órgãos responsáveis pela implementação do PAA, possam realizar frequentes acompanhamentos para verificar sua legitimidade de continuidade ou não. Fato é que na arena das políticas públicas os diferentes atores disputam os mesmos recursos, alcançando melhores resultados os grupos sociais mais articulados e consolidados (DIAS; MATOS, 2012).

No âmbito da insatisfação quanto à documentação exigida para a participação no PAA (Questão 25), uma parcela dos entrevistados considerou que há muita "burocracia" para a participação no Programa e, ainda, havia pedidos duplicados de documentação entre a CONAB e os órgãos que emitem a DAP. Essa situação pode ser compreendida como sendo resultado de, entre outras, por dois aspectos. De um lado os agricultores não estão habituados e, em grande medida, pouco capacitados a realizar contratos para venda de seus produtos. Por outro lado, os órgãos operadores do PAA, em seus diferentes níveis, necessitam registrar e documentar todos os procedimentos necessários a operacionalização do Programa. Um processo de capacitação dos beneficiários e uma constante melhoria dos processos formais pelos gestores, entre outros aspectos, poderá mitigar tal insatisfação no tocante a burocracia para operar o PAA. Deste modo, faz-se necessário frisar que a avaliação de uma política pública se torna sempre necessária, pois ela permite que os atores sociais - beneficiários, Governo e outros - possam realizar uma série de ações com o propósito de melhorar os resultados da política em curso.

Outros agricultores mostraram-se insatisfeitos com os preços pago pela CONAB aos produtos do PAA
(Questão 31). Esse indicador foi o que representou um maior grau de insatisfação $(61,4 \%)$ na pesquisa realizada. Contudo, ao se manifestarem sobre se os preços pagos para seus produtos permitiram cobrir os custos de produção 29,8\% disseram estar 'muito satisfeitos' e 63,2\% ‘satisfeitos'. Tendo em vista a lógica de cálculo dos custos de produção pelos agricultores familiares, na qual a mão-de-obra não en tra como custo, pois não gerenciam seus empreendimentos como se fosse empresa capitalista, fica observado os aspectos relativos a remuneração do trabalho realizado. Neste sentido, demonstram estarem insatisfeitos com os preços recebidos, porém é importante frisar que, como destacado acima, mostraram-se satisfeitos quanto a melhoria de qualidade de vida possibilitada pela inserção no mecanismo de comercialização do PAA. O estudo de Souza-Esquerdo e Bergamasco (2014) também analisou essa questão do preço e concluiu que isso pode ser um dos fatores que desestimula a participação de mais produtores. Diante disso, parece ser adequado realizar uma análise mais profunda sobre os preços dos produtos e a renda obtida pelas famílias, por meio da remuneração da sua mão-deobra obtida.

Iniciando a análise do MAS, a partir dos dados absolutos do Quadro 7, procedeu-se a análise da pontuação obtida nesse conjunto de questões. Estas respostas, junto aos seus respectivos pesos, permitiram a elaboração do grau de satisfação em relação ao PAA (Quadro 8). O índice encontrado de 2,61 (Quadro 8) mostrou que os agricultores familiares estavam satisfeitos (ver Quadro 5) com o PAA.

Quadro 8 . Alocação de Pesos e Elaboração do Grau de Satisfação dos Agricultores Familiares em relação ao PAA

\begin{tabular}{|c|c|c|}
\hline (a) $\mathrm{N}^{\mathrm{o}}$ Respostas & (b) Pesos & $\begin{array}{c}(\mathrm{a} X \mathrm{X}) \\
\text { Resultado }\end{array}$ \\
\hline$A=214$ & 4 & 856 \\
\hline$B=635$ & 3 & 1905 \\
\hline$C=161$ & 2 & 322 \\
\hline $\mathrm{D}=260$ & 1 & 260 \\
\hline$E=10$ & 0 & 0 \\
\hline \multicolumn{2}{|r|}{ (c) Soma dos Resultados } & 3343 \\
\hline \multicolumn{2}{|r|}{ (d) $\mathrm{N}^{\mathrm{o}}$ de questões } & 1280 \\
\hline \multicolumn{2}{|r|}{$(\mathrm{e}=\mathrm{c} / \mathrm{d})$ Resultado } & 2,61 \\
\hline
\end{tabular}

Fonte: Dados da pesquisa de campo (2015). 
Considerando o perfil dos agricultores familiares do município de Foz de Iguaçu foi possível verificar que participaram do PAA-CDS com bastante êxito, pois observou-se que são agricultores familiares experientes, há muitos anos no município e que, além disso, recebem apoio da Prefeitura e de ONGS. Segundo Basso (2004) a experiência dos agricultores no interior da dinâmica socioeconômica tem possibilitado sua construção no papel de sujeitos, pois, ao experimentarem situações e relações produtivas, mobilizavam-se para, também, se colocarem enquanto atores sociais com interesses próprios. Por meio dessas características foi possível inferir que o perfil dos agricultores familiares e o contexto da região está estreitamente relacionado ao grau de satisfação dos agricultores familiares.

A modalidade do PAA-CDS tem cumprido com seus objetivos principais na região de Foz do Iguaçu/PR, pois o resultado, por meio da aplicação do modelo MAS, demonstrou que os agricultores familiares estavam satisfeitos com a política pública. No entanto, foi possível verificar que o resultado esteve muito mais próximo dos 'indeciso' do que em relação aos 'muito satisfeito'. Isso se deve justamente ao grau de insatisfação de alguns agricultores, como já exposto anteriormente.

Assim, alinhado ao princípio da efetividade das ações públicas, faz-se necessário encontrar maneiras de atenuar a insatisfação desses agricultores familiares. A alternativa mais viável seria contribuir com melhorias na política pública, alterando-a para que todos os atores estejam alinhados e satisfeitos, segundo suas expectativas.

É importante ressaltar que o modelo MAS foi proposto para ser aplicado a diferentes regiões do Brasil, permitindo verificar os perfis dos diferentes agricultores familiares, espalhados no território nacional. Isso possibilitaria conhecer o perfil e o grau de satisfação desses agricultores familiares, não só na esfera municipal, como também em âmbito nacional. Com tais informações, seria possível implementar alterações na política pública que permitiriam melhorias a nível local e algumas mais abrangentes.

\section{VARIÁVEL III - Grau de satisfação em relação à gestão da cooperativa ou associação}

O Quadro 9 apresenta as proporções para cada escala das questões 42 a 51. No geral, os agricultores familiares disseram estar muito satisfeito (19\%); satisfeitos $(50 \%)$; indecisos/neutros (17\%); insatisfeitos (13\%); muito insatisfeitos (1\%).

Da mesma forma ao que ocorreu com o grau de satisfação em relação ao PAA, 50\% manifestaram estar satisfeitos com o trabalho da COAFASO, com destaque às questões $43,47,48$ e 50 , principalmente quanto aos indicadores de assistência técnica da cooperativa; à forma de participação nas assembleias; à maneira de resolução de conflitos e também quanto à transparência das informações. Por meio desses indicadores, notou-se que a gestão da COAFASO estava em sintonia com seus cooperados, havendo um ambiente bastante propício para a manutenção e desenvolvimento dos princípios do cooperativismo moderno, indicados por Gawlak (2007), que permite uma maior possibilidade de levar o grupo ao sucesso coletivo.

Por outro lado, $17 \%$ estavam Indecisos/Neutros, destacando-se as questões 42, 44 e 46. Esses agricultores familiares não tiveram opinião formada sobre temas importantes da gestão da cooperativa, como participação na elaboração da proposta do PAA (questão 42); apoio operacional da cooperativa (questão 44); e forma que os diretores da COAFASO dialogam com os cooperados (questão 46). De certa forma, esses indicadores representam questões que envolvem o relacionamento entre os cooperados, incluindo aqueles membros que estão na direção desses empreendimentos solidários. Sendo assim, certo nível de discordância pode ser tolerado, considerando o processo cognitivo e experiência de vida de cada membro. Pinheiro e Paes de Paula (2016), ressaltam a ideia de deslocar a lógica de responsabilidade coletiva, geralmente pautada na máxima 'o que é público não é de ninguém', para a lógica de responsabilidade individual coletiva, colocando os membros da organização como responsáveis para assumir o comprometimento com a cooperativa, praticando assim, uma gestão verdadeiramente compartilhada.

Outros 13\% declararam estar insatisfeitos em relação à gestão da Cooperativa, destacando principalmente a falta de apoio operacional da COAFASO (questão 44) e os canais de reclamação (questão 51). Referente ao indicador 'canais de reclamação', a maioria dos entrevistados se declararam insatisfeitos. Nas observações dos formulários de pesquisa, revelaram que não existia um canal de reclamação propriamente 
dito, pois as reclamações ou críticas eram direcionadas aos diretores da cooperativa ou bem nas assembleias. Como já indicado, as cooperativas como qualquer organização, devem buscar a eficiência e eficácia, visando entender, além das relações de mercados, à satisfação de seus próprios cooperados.

Quadro 9. Proporções de Respostas da Variável III - Grau de Satisfação da Gestão da Cooperativa

\begin{tabular}{|c|c|c|c|c|c|c|}
\hline & $\begin{array}{l}\text { VARIÁVEL III } \\
\text { GRAU DE SATISFAÇÃO EM RELAÇÃO ÀS ORGANIZAÇÕES } \\
\text { FORNECEDORAS DO PAA } \\
\text { (COOPERATIVAS OU OUTRAS ASSOCIAÇÕES) }\end{array}$ & 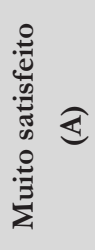 & 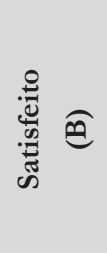 & 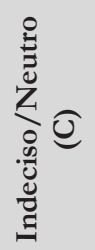 & 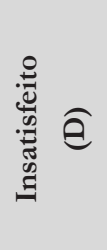 & 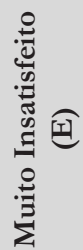 \\
\hline & $\begin{array}{l}\text { ação aos aspectos de gestão da Cooperativa ou Associação, indique o grau de } \\
\text { ção: }\end{array}$ & & & & & \\
\hline 42. & $\begin{array}{l}\text { Com o nível de sua participação na elaboração da proposta do PAA pela Cooperativa } \\
\text { ou Associação }\end{array}$ & $21,1 \%$ & $59,6 \%$ & $19,3 \%$ & $0 \%$ & $0 \%$ \\
\hline 43. & Com a assistência da Cooperativa ou Associação sobre os procedimentos do PAA & $15,8 \%$ & $64,9 \%$ & $15,8 \%$ & $3,5 \%$ & $0 \%$ \\
\hline 44. & $\begin{array}{l}\text { Com o apoio operacional da Cooperativa ou Associação (ajuda para embalagens, } \\
\text { transporte e certificação de orgânicos) }\end{array}$ & $7,0 \%$ & $14,0 \%$ & $45,6 \%$ & $31,6 \%$ & $1,8 \%$ \\
\hline 45. & $\begin{array}{l}\text { Com as oportunidades dadas pela Cooperativa ou Associação para a participação de } \\
\text { todos os cooperados }\end{array}$ & $36,8 \%$ & $57,9 \%$ & $3,5 \%$ & $1,8 \%$ & $0 \%$ \\
\hline 46. & Com a forma como os diretores/as dialogam e atendem os associados(as) & $12,3 \%$ & $56,1 \%$ & $28,1 \%$ & $3,5 \%$ & $0 \%$ \\
\hline 47. & Com a forma de participação nas Assembleias Gerais da Cooperativa ou Associação & $10,5 \%$ & $72 \%$ & $14,0 \%$ & $3,5 \%$ & $0 \%$ \\
\hline 48. & $\begin{array}{l}\text { Com as formas adotadas pelos diretores da Cooperativa ou Associação para resolver os } \\
\text { conflitos entre a cooperativa ou Associação e os filiados }\end{array}$ & $14,0 \%$ & $72 \% \%$ & $12,2 \%$ & $1,8 \%$ & $0 \%$ \\
\hline 49. & Com as estratégias da Cooperativa ou Associação para alcançar novas parcerias & $68,4 \%$ & $19,3 \%$ & $5,3 \%$ & $7,0 \%$ & $0 \%$ \\
\hline 50. & Com a transparência das informações da Cooperativa ou Associação aos filiados & $3,5 \%$ & $80,7 \%$ & $7,0 \%$ & $8,8 \%$ & $0 \%$ \\
\hline 51. & Com os canais de reclamações existentes & $0 \%$ & $8,8 \%$ & $19,3 \%$ & $68,4 \%$ & $3,5 \%$ \\
\hline Tot & absoluto & 108 & 288 & 97 & 74 & 3 \\
\hline Tot & reral & $19 \%$ & $50 \%$ & $17 \%$ & $13 \%$ & $1 \%$ \\
\hline
\end{tabular}

Fonte: Pesquisa de campo, 2015.

Efetuando a análise através do MAS, a partir dos dados absolutos do Quadro 09, procedeu-se à avaliação da pontuação obtida nesse conjunto de questões. Estas respostas, junto aos seus respectivos pesos, permitiram a elaboração do grau de satisfação em relação à gestão da Cooperativa ou Associação (Quadro 10). O índice encontrado de 2,74 (quadro 10) mostrou que os agricultores familiares estão satisfeitos (ver Quadro 5) com a gestão da Cooperativa.

Os agricultores familiares declararam estar satisfeitos com a forma da gestão da cooperativa. Isso demonstra, de certa maneira, que a organização tem se guiado pelos princípios do cooperativismo e fomentado uma gestão democrática e participativa, sem retirar a autonomia e independência dos cooperados. Observou-se, inclusive, através dos comentários dos agricultores familiares, que a avaliação positiva da gestão da cooperativa deveu-se também à participação da organização em outros projetos, considerando principalmente a participação no PNAE.

Apesar dessa avaliação positiva, notou-se que há um considerável percentual que preferiu manter a neutralidade. Observou-se também que há aspectos concretos a serem melhorados, na busca da satisfação de mais cooperados, visando uma equidade de tratamento, renda e sentimento de pertencimento ao grupo. 
Quadro 10 . Alocação de Pesos e Elaboração do Grau de Satisfação dos Agricultores Familiares em Relação à Gestão da Cooperativa ou Associação

\begin{tabular}{|c|c|c|}
\hline (a) $\mathbf{N}^{\mathbf{o}}$ Respostas & (b) Pesos & $\begin{array}{c}\text { (a X b) } \\
\text { Resultado }\end{array}$ \\
\hline $\mathrm{A}=108$ & 4 & 432 \\
$\mathrm{~B}=288$ & 3 & 864 \\
$\mathrm{C}=97$ & 2 & 194 \\
$\mathrm{D}=74$ & 0 & 74 \\
$\mathrm{E}=3$ & (c) Soma dos Resultados & 1564 \\
\hline \multicolumn{2}{r|}{ (d) $\mathrm{N}^{\text {o }}$ de questões } & 570 \\
& (e = c / d) Resultado & $\mathbf{2 , 7 4}$ \\
\hline
\end{tabular}

Fonte: Dados da pesquisa de campo (2015).

No intuito de avaliar novas percepções e grau de satisfação dos agricultores familiares, fez-se a análise bidimensional, com aplicação do teste de independência (Tabela 1), entre algumas questões pesquisadas. Dos nove testes realizados, apenas houve relação significativa a $5 \%$ de probabilidade, entre os resultados da tabela de dupla-entrada obtida do cruzamento das questões 41 versus 31 ( $\mathrm{p}$-valor = $0,03<0,05)$, sendo as demais situações consideradas independentes entre si ( $\mathrm{p}$-valor $>0,05)$. Ou seja, podese inferir que existe relação entre o grau de satisfação ou insatisfação com o PAA e o grau de satisfação ou insatisfação com os preços pagos pelos produtos. Desta forma, a variável preço possuiu grande influência na visão dos agricultores familiares, ocasionando um nível de insatisfação com toda a política pública do PAA, a partir da percepção dos baixos preços.

Tabela 1 . Teste de independência aplicado a questões levantadas com os agricultores familiares

\begin{tabular}{cc}
\hline Análises Bidimensionais & p-valor \\
\hline (Q4 X Q14) & $0,50^{\mathrm{ns}}$ \\
(Q10 X Q31) & $0,36^{\mathrm{ns}}$ \\
(Q8 X Q45) & $0,94^{\mathrm{ns}}$ \\
(Q5 X 32) & $0,64^{\mathrm{ns}}$ \\
(Q45 X 14) & $0,36^{\mathrm{ns}}$ \\
(Q41 X 38) & $0,10^{\mathrm{ns}}$
\end{tabular}

$\begin{array}{ll}\text { (Q41 X 31) } & 0,03 * \\ \text { (Q41 X 43) } & 0,95^{\mathrm{ns}} \\ (\mathrm{Q} 41 \text { X 46) } & 0,56^{\mathrm{ns}}\end{array}$

Nota: * relação estatística significativa ( $\mathrm{p}$-valor $<0,05)$; ${ }^{\text {ns }}$ relação não significativa ( $\mathrm{p}$-valor $>0,05)$.

Fonte: Dados da pesquisa, 2015.

\section{Etapa - Propostas de Intervenção}

A proposta de intervenção sugerida teve dois direcionamentos. O primeiro foi a proposição de melhorias na política pública PAA, com base no grau de satisfação dos fornecedores (agricultores familiares) dos produtos desse programa, no sentido de atenuar possíveis debilidades do PAA.

O segundo direcionamento da proposta de intervenção foi orientado aos diretores da COAFASO, apresentando-lhes possíveis alternativas para minimizar as prováveis insatisfações dos cooperados, em relação à forma de gestão da organização.

A intervenção utilizada foi do tipo consultoria, pois teve como objetivo avaliar os processos e métodos da política pública e da gestão da COAFASO. Consultorias são uma espécie de serviço fornecido por pessoas altamente treinadas e qualificadas, solicitadas a auxiliar, de maneira prática e independente à organização, na identificação de problemas de gerenciamento e recomendações de soluções (Oliveira, 2005).

A partir dos resultados sobre os indicadores pesquisados e discutidos na etapa anterior, apresentamse a seguir duas propostas de melhoria e intervenção. Uma direcionada aos órgãos públicos responsáveis pelo Programa PAA (MDS e CONAB), Quadro 11, e outra proposta de melhoria à Cooperativa COAFASO, Quadro 12. Considerando que o objetivo deste estudo era verificar possíveis debilidades do PAA e da gestão da Cooperativa, as propostas de intervenção estiveram direcionadas sob aqueles indicadores que receberam maiores pontuações na alternativa 'Indeciso/Neutro', 'Insatisfeito' e 'Muito Insatisfeito'. 
Quadro 11 . Proposta de Melhoria na Política Pública PAA

\begin{tabular}{|c|c|c|}
\hline Indicador & Debilidade & Intervenção \\
\hline $\begin{array}{l}\text { Apoio das organizações } \\
\text { de assistência e extensão } \\
\text { rural }\end{array}$ & $\begin{array}{l}\text { Verificou-se que no município de Foz do Iguaçu há duas } \\
\text { Organizações não Governamentais - Cooperativa de Trabalho e } \\
\text { Assistência Técnica do Paraná (Biolabore) e o Centro de Apoio } \\
\text { oo Pequeno Agricultor (Capa) -, que com o apoio da Itaipu, } \\
\text { tem prestado assistência aos agricultores familiares. No entanto, } \\
\text { observou-se a reduzida participação da Emater. Sua participação } \\
\text { é essencial, uma vez que haverá regiões do Brasil que não contam } \\
\text { com o apoio de ONG e haverá a possibilidade de os agricultores } \\
\text { familiares ficarem desassistidos. }\end{array}$ & $\begin{array}{l}\text { Estabelecer critérios para a } \\
\text { participação efetiva da Emater e, } \\
\text { onde ela não tenha condições de } \\
\text { atender aos agricultores familiares, } \\
\text { sugere-se que esses agricultores } \\
\text { possam ser beneficiários } \\
\text { prioritários dos editais do Plano } \\
\text { Nacional de Assistência Técnica e } \\
\text { Extensão Rural. }\end{array}$ \\
\hline $\begin{array}{l}\text { Apoio recebido pelo } \\
\text { governo (prefeitura, } \\
\text { Estado ou CONAB) }\end{array}$ & $\begin{array}{l}\text { Apesar do significativo apoio da prefeitura, é quase nulo o apoio } \\
\text { do Estado do Paraná e da CONAB. Considerando que o êxito } \\
\text { da Política Pública PAA depende de todos os atores, recomenda- } \\
\text { se uma maior aproximação do Estado do Paraná, principalmente } \\
\text { da CONAB, com os agricultores familiares. O Diretor da } \\
\text { COAFASO e os agricultores revelaram que desde a inauguração } \\
\text { da Cooperativa não tiveram nenhuma capacitação por parte da } \\
\text { CONAB. Também relataram que a CONAB realizou algumas } \\
\text { visitas, mas com o objetivo de fiscalizar os produtos (qualidade, } \\
\text { armazenamento e distribuição). }\end{array}$ & $\begin{array}{l}\text { Aproximação da CONAB } \\
\text { junto aos agricultores familiares } \\
\text { desenvolvendo atividades de } \\
\text { capacitação e informação. }\end{array}$ \\
\hline $\begin{array}{l}\text { Grupos prioritários } \\
\text { definidos pelo MDS } \\
\text { (CadÚnico; assentados; } \\
\text { indígenas, quilombolas } \\
\text { e comunidades } \\
\text { tradicionais; mulheres; e } \\
\text { produtos orgânicos ou } \\
\text { agroecológicos). }\end{array}$ & $\begin{array}{l}\text { Muitos dos agricultores familiares não concordam com os } \\
\text { grupos prioritários definidos pelo MDS, principalmente os } \\
\text { agricultores que possuem uma parcela de terra menor do que a } \\
\text { de muitos assentados. No entanto, estes só podem participar da } \\
\text { proposta da CONAB caso não seja totalmente atendida pelos } \\
\text { grupos prioritários. Ressalta-se que os grupos prioritários foram } \\
\text { estabelecidos em } 2003 \text {, através do Programa Fome Zero e que já } \\
\text { se passaram } 12 \text { anos dessa política pública afirmativa. }\end{array}$ & $\begin{array}{l}\text { Reavaliar a política pública } \\
\text { afirmativa dos grupos prioritários, } \\
\text { visando verificar se uma atual } \\
\text { igualdade de condições, entre } \\
\text { todos os grupos causaria prejuízos } \\
\text { sociais a alguns deles. }\end{array}$ \\
\hline $\begin{array}{l}\text { Documentação exigida } \\
\text { (CPF e DAP). }\end{array}$ & $\begin{array}{l}\text { Os agricultores familiares e as cooperativas se queixam, pois já } \\
\text { atualizam a DAP no MDA. Porém, a cada proposta, devem enviar } \\
\text { novamente o documento impresso. Eles ressaltam que para a } \\
\text { participação no PAA - modalidade Termo de Adesão-Prefeitura } \\
\text { - não é necessário entregar documentos físicos. }\end{array}$ & $\begin{array}{l}\text { Realizar cruzamento automático } \\
\text { de dados da DAP entre o MDA } \\
\text { e a CONAB, no momento } \\
\text { da inserção das propostas } \\
\text { cadastradas, sem a necessidade do } \\
\text { uso da documentação física. }\end{array}$ \\
\hline $\begin{array}{l}\text { Condições e obrigações } \\
\text { estabelecidas no termo } \\
\text { de compromisso }\end{array}$ & $\begin{array}{l}\text { Os agricultores familiares consideraram uma burocracia a assi- } \\
\text { natura do termo de compromisso, pois pensam que a Cooperativa } \\
\text { já assumiria os compromissos, sendo eles corresponsáveis apenas } \\
\text { pelos atos, enquanto filiados. A cooperativa tem dificuldade de } \\
\text { explicar aos agricultores familiares a necessidade da assinatura do } \\
\text { termo de compromisso individual e isso acarreta atraso, pois é } \\
\text { preciso convencê-los e então recolher todas as suas assinaturas. }\end{array}$ & $\begin{array}{l}\text { Capacitação/seminário, por } \\
\text { parte da CONAB, sobre os } \\
\text { procedimentos burocráticos } \\
\text { e necessários do PAA-CDS, } \\
\text { tendo em vista a importância do } \\
\text { termo de compromisso, tanto } \\
\text { para a Cooperativa como para a } \\
\text { CONAB. }\end{array}$ \\
\hline $\begin{array}{l}\text { Ajuda no transporte dos } \\
\text { produtos pela prefeitura } \\
\text { ou pela CONAB, } \\
\text { especialmente para } \\
\text { produtos como leite e } \\
\text { queijos. }\end{array}$ & $\begin{array}{l}\text { Os agricultores familiares declararam insatisfação quanto ao apoio } \\
\text { recebido para o transporte das mercadorias, pois alguns produtos } \\
\text { necessitam ser transportados em veículos especiais e isso acarreta } \\
\text { aumento no preço da produção. }\end{array}$ & $\begin{array}{l}\text { Realizar estudo de viabilização } \\
\text { comercial e, se for pertinente, } \\
\text { oferecer linha de crédito específica } \\
\text { para a aquisição de veículos para } \\
\text { transporte de mercadorias pelas } \\
\text { cooperativas. }\end{array}$ \\
\hline
\end{tabular}


Preços pagos aos produtos do PAA

Quantidade de membros familiares que trabalham na agricultura familiar
Os agricultores familiares entendem que seus produtos não podem ser comparados com os produtos convencionais dos supermercados, considerando principalmente suas especificidades de produção, pois apesar de muitos produtos não possuírem o selo de orgânicos, vários são produzidos com um manejo diferenciado. Os agricultores familiares ressaltam que, no PNAE, esses produtos com manejo diferenciado recebem um melhor preço. Além disso, a maioria dos agricultores familiares, dado seu grau de instrução, são incapazes de ler e entender as resoluções e procedimentos para estabelecimento do cálculo do preço.

$33 \%$ dos entrevistados revelaram que apenas 1 ou 2 membros trabalham na agricultura familiar e que isso impacta negativamente em algumas das fases da produção, principalmente na colheita. Esses produtores se veem obrigados a contratar mão de obra e isso repercute no custo da produção.
Valorização dos produtos oriundos da agricultura familiar, bem como capacitar as cooperativas para explicar aos agricultores a formação de preços.

Disponibilizar um serviço de ATER, objetivando que o agricultor identifique o sistema produtivo adequado à sua mão de obra disponível.

Fonte: Elaborado pelo Autores (2015).

Quadro 12 . Proposta de Melhoria na Gestão da Cooperativa - COAFASO

\begin{tabular}{|c|c|c|}
\hline INDICADOR & DEBILIDADE & INTERVENÇÃO \\
\hline $\begin{array}{l}\text { Participação na } \\
\text { elaboração da proposta } \\
\text { do PAA }\end{array}$ & $\begin{array}{l}\text { Notou-se que muitos agricultores familiares se mantiveram } \\
\text { neutros quanto à satisfação na construção da proposta do PAA. } \\
\text { Esse fato pode levar a uma certa centralização da diretoria da } \\
\text { COAFASO, pois há muitos agricultores familiares que não se } \\
\text { posicionam sobre os assuntos. }\end{array}$ & $\begin{array}{l}\text { Abordar, nas assembleias gerais ou } \\
\text { em outros eventos da cooperativa, } \\
\text { a importância da participação } \\
\text { dos filiados em todas as etapas } \\
\text { do processo de cadastramento da } \\
\text { proposta. }\end{array}$ \\
\hline $\begin{array}{l}\text { Apoio operacional } \\
\text { da Cooperativa ou } \\
\text { Associação (ajuda para } \\
\text { embalagens, transporte } \\
\text { e certificação de } \\
\text { orgânicos) }\end{array}$ & $\begin{array}{l}\text { Os agricultores familiares manifestaram que, em relação às } \\
\text { embalagens e ao transporte, há pouco apoio da Cooperativa. } \\
\text { Também comentaram que estariam de acordo em compartilhar } \\
\text { os custos, pois, neste caso, ao contratar serviços para todos os } \\
\text { agricultores familiares, se alcançariam melhores preços. }\end{array}$ & $\begin{array}{l}\text { Realizar plano de contratação } \\
\text { (embalagens e transporte), com } \\
\text { detalhamento de preços e custos, } \\
\text { apresentando aos agricultores a } \\
\text { previsão de rateio. }\end{array}$ \\
\hline $\begin{array}{l}\text { Forma como os } \\
\text { diretores(as) dialogam } \\
\text { e atendem os } \\
\text { associados(as) }\end{array}$ & $\begin{array}{l}\text { Mesmo reconhecendo que o relacionamento entre dirigentes e } \\
\text { cooperados são complexos, a cooperativa deveria capacitar sua } \\
\text { equipe, visando um atendimento imparcial e equânime entre } \\
\text { os filiados }\end{array}$ & $\begin{array}{l}\text { Capacitar a equipe da gestão da } \\
\text { Cooperativa sobre temas como: } \\
\text { atendimento, negociação e } \\
\text { resolução de conflitos. }\end{array}$ \\
\hline $\begin{array}{l}\text { Canais de reclamação } \\
\text { existentes }\end{array}$ & $\begin{array}{l}\text { A maioria dos agricultores familiares declararam desconhecer } \\
\text { se a Cooperativa tinha algum canal de reclamação. Muitos } \\
\text { ressaltaram a importância da realização da reclamação de } \\
\text { maneira não identificável, pois inferem que alguns agricultores } \\
\text { podem ter queixas, mas não reclamam, pelo receio de se } \\
\text { indisporem junto aos diretores da Cooperativa }\end{array}$ & $\begin{array}{l}\text { Criar formulário, no website, para } \\
\text { recebimento de reclamação dos } \\
\text { cooperados, sem a possibilidade de } \\
\text { serem identificados. }\end{array}$ \\
\hline
\end{tabular}

Fonte: Elaborado pelo Autores (2015). 


\section{Considerações Finais}

O objetivo geral deste artigo foi o de demostrar o grau de satisfação dos agricultores familiares em relação ao Programa de Aquisição de Alimentos (PAA), modalidade Compra com Doação Simultânea (CDS), do Governo Federal, bem como, do grau de satisfação dos agricultores familiares em relação à gestão da cooperativa (COAFASO).

De modo geral, verificou-se que os agricultores familiares estão satisfeitos com o PAA e com a gestão da cooperativa. Contudo, e em diálogo com outros estudos correlatos realizados sobre a temática, foi possível constatar debilidades presentes em alguns dos indicadores de avaliação do PAA, a partir do instrumento MAS construído para fins de avaliação de políticas públicas. Destacou-se entre os indicadores com debilidades, o que investigou a percepção dos agricultores familiares em relação ao preço pago pelo PAA sobre produtos adquiridos.

Considerando que o Modelo MAS é uma ferramenta composta por uma ampla gama de indicadores, o Modelo é uma alternativa de monitoramento e avaliação da política pública PAA, uma vez que pode ser aplicado a várias regiões do país. A partir da análise dos dados e de suas conclusões é possível oportunizar ajustes em seus mais diferentes indicadores objetivando aprimorar a operacionalidade da política pública, bem como consolidar os indicadores que se mostram adequados. Nesse sentido, o estudo revelou que a avaliação da política pública pode permitir ganhos organizacionais e sociais. Sociais porque permite detectar a satisfação de um dos atores participantes do PAA, nesse caso os agricultores familiares.

A pesquisa atendeu seu objetivo principal, uma vez que na consolidação e cálculo das respostas, foi possível constatar o grau de satisfação dos agricultores familiares de maneira objetiva e conclusiva e, por meio de análises unidimensional e bidimensional, foi possível inferir pontos fortes e debilidades em relação ao PAA-CDS e à gestão das cooperativas e associações. Essa gama de informações permitiu a realização das propostas de intervenção.

Agricultores familiares satisfeitos com as políticas públicas gera um ambiente social, organizativo e institucional, na forma de um capital social, favorável ao desenvolvimento rural que, por sua vez, abre espaços para melhoria de qualidade de vida ao conjunto de atores do meio rural.
Atualmente observa-se que os Governos estão mais atentos em promover políticas públicas que possam mitigar o nível de pobreza com programas que possam valorizar esforços de diversos atores sociais individuais, coletivos ou públicos - criando ambiente de sinergias para qualificar a operacionalização de programas. Além disso, políticas com capacidades de atender categorias sociais que, por longos períodos, estiveram sem acesso a recursos e meios essenciais para as práticas de desenvolvimento rural. O PAA é uma importante iniciativa pública no sentido de possibilitar aos seus beneficiários - fornecedores e recebedores - meios viáveis para fazer a agricultura com inclusão social e atender a questão da segurança alimentar da sociedade atual.

Como limite da pesquisa, o fato que ter aplicado o Modelo em apenas uma Cooperativa foi uma limitação, considerando que as informações foram coletadas de indivíduos e cada um desses possuem processos de cognição diferenciado. Assim, a aplicação em apenas uma organização pode ter causado algum viés à pesquisa.

Como agenda de pesquisa, se poderia investigar a real relação entre o PAA e a sustentabilidade - esta que defende a indissociabilidade entres os pilares: ambiental, social e econômico. Mesmo sendo um dos objetivos do PAA o fomento à sustentabilidade, verificaram-se raríssimos estudos que investigaram essa relação.

Uma segunda sugestão, de cunho mais técnico e considerando que a aplicação manual do MAS é dispendioso, seria a transformação do Modelo MAS em um aplicativo, capaz de coletar as informações dos agricultores familiares através de aparelho móvel celular, tablet etc. -, sendo uma inovação criativa para coletar dados avaliativos das políticas públicas.

\section{Referências}

ANDRADE, M. C.; ALVES, D. C. Cooperativismo e agricultura familiar: um estudo de caso. RAIMED

- Revista de Administração IMED, v. 3, n. 3, p. 194-208, 2013.

ASSIS, S. C. R.; PRIORE, S. E.; FRANCESCHINI, S. C. C. Impacto do Programa de Aquisição de Alimentos na segurança alimentar e nutricional dos agricultores. Ciência \& Saúde Coletiva, v. 22, n. 2, p. 617-626, 2017. 
BACEN - Banco Central do Brasil. FAQ -

Programa Nacional de Fortalecimento da

Agricultura Familiar. 2016. Disponível em:

<http://www.bcb.gov.br/?PRONAFFAQ>. Acesso em 12 set. 2016.

BASSO, D. A produção e a gestão de políticas públicas de desenvolvimento rural pelos agricultores familiares de Dois Vizinhos, Paraná. In S.

SCHENEIDER, SILVA, M. K.; MARQUES, P.

E. M. (Orgs.). Políticas Públicas e Participação

Social no Brasil Rural. 2a ed. Porto Alegre: Editora da UFRGS, 2004.

BERTOLINI, G. R. F.; ROJO, C. A.; LEZANA, A. G. R. Modelo de análise de investimentos para fabricação de produtos ecologicamente corretos.

Gest. Prod., São Carlos, v. 19, n. 3, p. 575-588, 2012.

BRANDALISE, L. T. A percepção do consumidor na análise do ciclo de vida do produto: um modelo de apoio à gestão empresarial. Cascavel: EDUNIOESTE, 2008.

CONAB - Companhia Nacional de Abastecimento. Agricultura e abastecimento alimentar: políticas públicas e mercado agrícola. Brasília: CONAB, 2009.

Modalidades do PAA. 2016. Disponível em: <http://www.mds.gov.br/segurancaalimentar/ aquisicao-e-comercializacao-da-agricultura-familiar/ entenda-o-paa/modalidades-1/modalidades $>$. Acesso em jul. 2016.

BRASIL. Decreto n. ${ }^{\circ}$ 1.946, de 28 de junho de 1996. Cria o Programa Nacional de Fortalecimento da Agricultura Familiar - PRONAF. Diário Oficial da República Federativa do Brasil. Brasília, 1996. Disponível em: < http://www.planalto.gov.br/ ccivil_03/decreto/D1946.htm>. Acesso em: 10 jul. 2017.

. Lei no 10.696, de 2 de Julho de 2003.

Dispõe sobre a repactuação e o alongamento de dívidas oriundas de operações de crédito rural e dá outras providências. Diário Oficial da República Federativa do Brasil. Brasília, 2003. Disponível em: $<$ http://www.planalto.gov.br/ccivil_03/leis/2003/ 110.696.htm>. Acesso em 8 de maio 2016.

. Decreto $n^{\circ} 7.775$, de 2 de Julho de 2012. Regulamenta o art. 19 da Lei no 10.696, de 2 de julho de 2003, que institui o Programa de Aquisição de Alimentos. Brasília. Diário Oficial da República
Federativa do Brasil. Brasília, 2012. Disponível em: <http://www.planalto.gov.br/ccivil_03/_ato20112014/2012/Decreto/D7775.htm>. Acesso em: 13 de maio 2016.

CONTERATO, M. A. at al. Mercantilização e mercados: a construção da diversidade da agricultura na ruralidade contemporânea. In SCHNEIDER, S.; GAZOLLA M. (Orgs.). Os atores do desenvolvimento rural: perspectivas teóricas e práticas sociais. Porto Alegre: Editora da UFRGS, 2011.

DIAS, R.; MATOS, F. Políticas públicas: princípios, propósitos e processos. São Paulo: Atlas, 2012.

SOUZA-ESQUERDO, V. F.; BERGAMASCO, S. M. P. P. Análise sobre o acesso aos programas de políticas públicas da agricultura familiar nos municípios do circuito das frutas. RESR, v. 52, n. 1, p. 205-222, 2014.

FARIA, C. A. P. A política da avaliação de políticas públicas. Revista Brasileira de Ciências Sociais, v. 20, n. 50, p. 97-169, 2005.

GAWLAK, A. Cooperativismo: primeiras lições. (3a ed.) Brasília: Sescoop, 2007.

Disponível em: <http://www.ocbmt.coop.br/ TNX/storage/webdisco/2009/12/28/outros/ f2acdd6df5f27518fd2c908db92a1275.pdf>. Acesso em 12 set. 2016.

GRISA, C.; SCHNEIDER, S. Três gerações de políticas públicas para a agricultura familiar e formas de interação entre sociedade e estado no Brasil.

RESR, v. 52, n. 1, p. 125-146, 2014.

HeIDEMANN, F. G.; SALM, J. F. (Orgs.). Políticas públicas e desenvolvimento. 3. ed. Brasília: Editora Universidade de Brasília, 2014.

HESPANHOL, R. A. M. Programa de Aquisição de Alimentos: limites e potencialidades de políticas de segurança alimentar para a agricultura familiar. Soc. \& Nat., v. 25, n. 3, p. 469-483, set./dez. 2013.

IBGE - Instituto Brasileiro de Geografia e Estatística. Censo Agricultura Familiar, 2006. Disponível em: <http://www.ibge.gov.br/home/ estatistica/economia/agropecuaria/censoagro/2006/ defaulttab_censoagro.shtm $>$. Acesso em: $12 \mathrm{dez}$. 2016. 
JANNUZZI, P. M. Avaliação de programas sociais no Brasil: repesando práticas e metodologias das pesquisas avaliativas. Planejamento e políticas públicas - PPP, n. 36, p. 251-275, 2011.

LIZOTE, S. A. at al. Análise de variáveis de relacionamento em cooperados: um estudo exploratório com associados a cooperativas de crédito. SEGET Simpósio de Excelência em Gestão da Tecnologia, 2013.

MAIA, C. M. Percepções que permeiam o conceito de agricultura familiar e a cronologia da luta pela sustentabilidade: panorama nacional e internacional. In: SOGLIO, F. D.; KUBO, R. R. (Orgs.).

Agricultura e Sustentabilidade. (Cap. 5, pp. 75-96). Porto Alegre: Editora da UFRGS, 2009.

MALLMANN, L. Z. at al. Análise da sustentabilidade ambiental e econômica de pequena propriedade rural do RS. Estudo \& Debate, v. 20, n. 1, p. 7-20, 2013.

MDA - Ministério do Desenvolvimento Agrário. Conceito de agricultura familiar. 2016.

Disponível em: <http://www.mds.gov.br/falemds/ perguntas-frequentes/bolsa-familia/programascomplementares/beneficiario/agricultura-familiar>. Acesso em 12 jul. 2016.

MDS - Ministério do Desenvolvimento Social e Combate à Fome - MDS. Manual operativo: modalidade compra com doação simultânea operação por meio de termo de adesão. (Versão 1.0, fevereiro de 2014). 2016a. Disponível em: <http://www.mds.gov.br/segurancaalimentar/ aquisicao-e-comercializacao-da-agricultura-familiar/ entenda-o-paa/manualPAA_06.03.pdf $>$. Acesso em: 02 fev. 2016.

Limite de compra de alimentos de agricultores familiares é ampliado. 2016b. Disponível em: <http://www.mds.gov.br/ saladeimprensa/noticias/2014/agosto/paa-limitede-compra-de-alimentos-de-agricultores-familiares-eampliado>. Acesso em 13 fev. 2016.

NASCIMENTO, D. T. Programa de Aquisição de Alimentos (PAA): Proposta de Modelo de Avaliação de Satisfação (MAS) dos Agricultores Familiares sobre os aspectos operacionais e socioeconômicos. Dissertação (Mestrado) Programa de Pós-Graduação em Administração, Universidade Estadual do Oeste do Paraná, Cascavel,
PR, 2015. Disponível em: < http://portalpos. unioeste.br/media/File/jose.tasca/DissertacaoDaniel-Teotonio-do-Nascimento.pdf $>$. Acesso em: 18 nov. 2016.

NASCIMENTO, D. T. at al. Produção científica sobre políticas públicas para a agricultura familiar: o Programa de Aquisição de Alimentos (PAA). Encontro Nacional dos Cursos de Graduação em Administração, 26, Foz do Iguaçu, PR, 2015. Anais eletrônicos... Disponível em: $<$ http://xxvi.enangrad.org.br/_assets/files/ 07201516503869dc358f7171fbc46936f974064cba09. pdf>. Acesso em: 12 jul. 2016.

NAZZARI, R. K.; ZIMMERMANN, P. Agricultura familiar, capital social e cooperativismo. In: BRANDALISE, L. T.; BERTOLINI, G. R. F. (Orgs.). Gestão das Unidades Artesanais: uma tecnologia social para capacitação de empreendedores da agricultura familiar. Cascavel, PR: Edunioeste, 2015, 185p.

OCB - Organização das Cooperativas Brasileiras. Conceito de Cooperativismo. 2016. Disponível em: $<$ http://www.ocb.org.br/site/cooperativismo/index. asp>. Acesso em 12 set. 2016.

PÉREZ, F. I. C. Agricultura familiar superando desafios em contextos concorrenciais: estudo de caso realizado na região Noroeste e Missões do Estado do Rio Grande do Sul. 2011. 148 f. Dissertação (Mestrado em Extensão Rural) Centro de Ciências Rurais, Universidade de Santa Maria, Santa Maria, RS, 2011. Disponível em: $<$ http://cascavel.ufsm.br/tede/tde_busca/arquivo. php?codArquivo=4439>. Acesso em: 15 de ago. 2016.

PGI - Plataforma de Gestão de Indicadores. Programa de Aquisição da Agricultura Familiar. 2015. Disponível em: < http://pgi.gov.br/pgi/ indicador/pesquisar>. Acesso em: 02 fev. 2016.

PINHEIRO, D. C.; PAES DE PAULA, A.

P. Autogestão e práticas organizacionais transformadoras: contribuições a partir de um caso empírico. Desenvolvimento Em Questão, v. 14, n. 33, p. 233-266, jan./mar., 2016.

ROSSI, F. R. Programa de Aquisição de Alimentos (PAA) da agricultura familiar no município de São Carlos: impactos 
socioeconômicos nos agricultores familiares beneficiários. Dissertação (Metrado) - Programa de Pós-graduação em Engenharia da Produção, Universidade Federal de São Carlos, São Carlos, SP, 2012. Disponível em: <https://repositorio.ufscar.br/ handle/ufscar/3704>. Acesso em: 05 mai. 2017.

SCHMITZ, H.; MOTA, D. M. Agricultura familiar: categoria teórica e/ou de ação política? Fragmentos de Cultura, Goiânia, v. 18, n. 5/6, p. 435-446, maio/ jun, 2008.

SCHNEIDER, S.; CAZELLA, A. A.; MATTEI, L. Histórico, caracterização e dinâmica do Pronaf Programa Nacional de Fortalecimento da Agricultura Familiar (1995-2003). In: SCHNEIDER, S.; SILVA, M. K; MARQUES, P. E. M. (Orgs.). Políticas Públicas e Participação Social no Brasil. 2. ed. Porto Alegre: Editora da UFRGS, 2009. p. 21-49.

SCHULTZ, G. Relações com o mercado e [re] construção das identidades socioprofissionais na agricultura orgânica. In: SCHNEIDER, S.; GAZOLLA, M. (Orgs.). Os atores do desenvolvimento rural: perspectivas teóricas e práticas sociais. Porto Alegre: Editora da UFRGS, 2011.

SECCHI, L. Políticas Públicas: Conceitos, esquemas de análise, casos práticos. 2. ed. São Paulo: Cengage Learning, 2013.

SILVA, M. K.; MARQUES, P. E. M. Democratização e políticas públicas de desenvolvimento rural. In: SCHNEIDER, S.; SILVA, M. K.; MARQUES, P. E. M. (Orgs.). Políticas Públicas e Participação Social no Brasil. (2a ed., pp. 9-20). Porto Alegre: Editora da UFRGS, 2009.

TANACA, E. K. T.; SOUZA, H. M. FILHO; GANGA G. M. D. Proposta de um modelo de avaliação dos fornecedores do Programa de Aquisição de Alimentos (PAA): o caso do município de São Carlos - SP. Gest. Prod., v. 21, n. 4, 781-792, 2014.

VERGARA, S. C. Projetos e relatórios de pesquisa em administração. 8. ed. São Paulo: Atlas, 2007. 